\title{
Research Paper \\ Comparison of the effectiveness of compassion focused therapy and dialectical behavior therapy on reducing the marital conflict of women on the threshold of the divorce
}

\author{
Seyedeh Mahboobeh Nabavi ${ }^{1}$, Masoud Shahbazi ${ }^{2}$, Amin Korai ${ }^{3}$ \\ 1. Ph.D Student in Counseling, Department of Counseling, Ahvaz Branch, Islamic Azad University, Ahvaz, Iran. \\ 2. Assistant Professor, Department of Counseling, Masjed Soleiman Branch, Islamic Azad University, Masjed Soleiman, Iran. \\ 3. Assistant Professor, Department of Counseling, Ahvaz Branch, Islamic Azad University, Ahvaz, Iran.
}

Citation: Nabavi S.M, Shahbazi M, Korai A. Comparison of the effectiveness of compassion focused therapy and dialectical behavior therapy on reducing the marital conflict of women on the threshold of the divorce. J of Psychological Science. 2021; 20(106): 1897-1912.

URL: https://psychologicalscience.ir/article-1-1079-fa.html
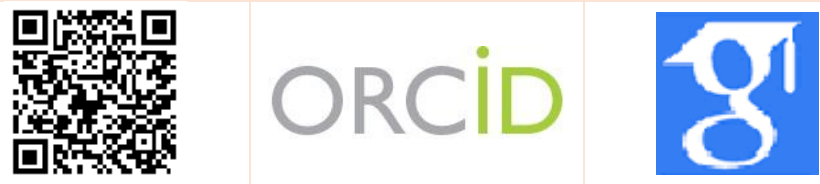

$\underline{10.52547 / J P S .20 .106 .1897}$

Keywords:
Marital conflict,
Compassion Focused
Therapy,
Dialectical Behavior
Therapy,
Women on the verge of
divorce

Received: 11 Dec 2020 Accepted: 07 Jan 2021

Available: 22 Dec 2021

\section{A B S T R A C T}

Background: Marital conflict can shake the foundations of cohabitation and provide the ground for an emotional and formal divorce. The effectiveness of dialectical behavioral therapy and compassionfocused therapy has been confirmed on various variables, but there is a research gap in the comparison and impact of these two therapies on marital conflict.

Aims: The aim of this study was to Comparison of the effectiveness of CFT and DBT on reducing the marital conflict of women on the threshold of divorce.

Methods: The research design was quasi-experimental and pre-test and post-test with a control group. The statistical population of this study included all women on the verge of divorce who had referred To counseling centers under the supervision of Sari Welfare Organization in 2018 due to marital disputes. Participants were selected by purposive sampling method. Then the questionnaire of marital conflict was performed on each of them. 45 women were selected as a sample based on the inclusion criteria and were randomly assigned to three groups of 15 people (two experimental groups and one control group). Data collection tool was Marital Conflict Questionnaire (MCQ) Sanaei et al. (2008). Then, the first experimental group underwent dialectical behavior therapy training for 8 sessions and the second experimental group underwent compassion-focused therapy training for 8 sessions. To analyze the data, SPSS24 software was used and the data were analyzed using multivariate analysis of covariance and Data were analyzed using multivariate analysis of covariance

Results: The results showed that in the post-test, the marital conflict of the subjects in the experimental groups had a significant decrease compared to the control group $(\mathrm{p}<0.001)$. However, the analysis of the Bephrone post hoc test did not show a difference between the effectiveness of dialectical behavior therapy and compassion-focused therapy on marital conflict in women on the verge of divorce

Conclusion: The results of this study suggest appropriate empirical support for dialectical behavior therapy and focused compassionate therapy. Psychologists and family counselors use these two therapies to improve marital conflict.

* Corresponding Author: Masoud Shahbazi, Assistant Professor, Department of Counseling, Masjed Soleiman Branch, Islamic Azad University, Masjed Soleiman, Iran.

E-mail: masoudshahbazi66@yahoo.com

Tel: (+98) 9166810412

2476-5740/ @ 2021 The Authors. This is an open access article under the CC BY-NC-ND license

(https://creativecommons.org/licenses/by-nc/4.0/). 


\section{Extended Abstract}

\section{Introduction}

Intimate communication is one of the most important emotional concerns in married life and also one of the important reasons for lasting marriages (Mirgain and Cordova, 2017).Over time and facing the various challenges of married life and the lack of necessary skills to improve the quality of the marital relationship, couples gradually become conflicted (Masumitabar et al, 2021).One of the treatment methods that is effective in various fields, including; Improving romantic relationships (Neff KD and Beretvas, 2013); Hope, self-esteem and mental health (Elaine Beaumont and Hollins, 2016); Intimate attitudes and reducing the desire for divorce and incompatibility and marital conflict (Dasht Bozorgi et al, 2017, Ragabi et al, 2017, Khalatbari, et al, 2018) have been successful, treatment focuses on compassion.

Compassion emphasizes the important principle that images, thoughts, experiences, and soothing external and external behaviors must be internalized; In this way, the person's mind calms down in dealing with these internal and external issues (Gilbert, 2014) as it reacts to external and external issues. In addition, in self-compassion, individuals learn not to shy away from unpleasant and painful feelings; As a result, they are able to learn from their experience and feel compassion for it (Irons, \& Lad, 2017). Another therapeutic intervention that has been used in the present study is Dialectical Behavior Therapy.

This method is a comprehensive treatment based on cognitive-behavioral therapy that was developed by Linhan in 1993 for suicidal patients (Natasha and Eman, 2019), but its effectiveness in various fields, including; Anxiety, Depression and Improving Resilience (Lathren, Bluth, Park, 2019 \& Baker, Caswell, Eccles, 2019), Helplessness Tolerance, SelfRegulation, Reduction of Negative Emotions (Robinson et al, 2018, Parisouz, Najarpoorian, Mohammadi, 2019), Increased resilience and psychological well-being, Marital conflicts (Ghasem Abadi, Khalatbari, Ghorban, Shiroudi, Rahmani,, 2019, Harley et al, 2008); It has been successful.
This method is very effective for people who want to control disturbing emotions. Using its techniques, individuals can have an undeniable impact on how they deal with conflicts and turmoil and make their interpersonal relationships satisfactory (McKay et al, 2007). Dialectical behavioral therapy teaches four categories of practical competence that fall into two components: the acceptance component (awareness awareness and tolerance of confusion) and the change component (emotional regulation and interpersonal efficiency) (DeCou et al, 2019). Considering that little research has been done in Iran on dialectical behavior therapy and compassion-focused therapy in relation to marital relationships, and since these factors are expected to have an effect on improving marital relations and reducing conflicts; Therefore, the present study aims to compare and answer the question "Is dialectical behavior therapy training and compassion-focused therapy effective in reducing boredom and marital conflict in women?", So that finally the results of this study can be Achieved effective strategies to survive and increase the health of marriages and prevent divorce.

\section{Method}

This study was a quasi-experimental study with a pretest and posttest design with a control group. The statistical population of this study included all women on the verge of divorce in Sari who were referred to counseling centers under the Welfare Organization in 2019 in order to prevent divorce and make a compromise.Among them, 45 women were selected by available sampling and randomly replaced in three groups of 15 (two experimental groups and one control group). After that, the first experimental group underwent compassion-focused treatment group training during 8 sessions of 2 hours, 1 session per week.The second experimental group underwent dialectical behavior therapy group training in 8 sessions of 2 hours, 1 session per week. SPSS 24 computer software was used to analyze the data and the data were analyzed using multivariate analysis of covariance. Significance level in this study was considered as $(=0.05$. In order to measure the rate of marital conflict in women, the 54-item Marital Conflict Questionnaire (MCQ) of Sanaei Zaker, Barati and Bustanipour (2008) was used. Reliability 


\section{Monthly Journal of Psychological Science}

of the whole questionnaire with Cronbach's alpha method on a group of 270 people, / 96. It has been reported (Sanaei et al., 2008, Quoted from Seidabadi et al, 2021).

In the present study, the reliability coefficients of the Marital Conflict Questionnaire were calculated using Cronbach's alpha method, which is 0.93 for the whole scale.

\section{Results}

Findings from demographic data showed that the women in the study had an age range of 21 to 60 years, among which the age range of 31 to 40 years had the highest frequency $(42.2 \%)$. Also, these women had the level of undergraduate to

Table 1. Mean and standard deviation of marital conflict scores of experimental and control groups in pre-test and post-test stages

\begin{tabular}{|c|c|c|c|c|}
\hline Variable & phase & Statistical index / Group & Average & Standard deviation \\
\hline \multirow{6}{*}{ Marital Conflict } & \multirow{3}{*}{ Pre-test } & DBT & 188.53 & 12.77 \\
\hline & & CFT & 188.07 & 21.99 \\
\hline & & Control & 186.40 & 18.09 \\
\hline & \multirow{3}{*}{ Post-test } & DBT & 133.33 & 11.80 \\
\hline & & CFT & 135.93 & 14.49 \\
\hline & & Control & 183.13 & 14.38 \\
\hline
\end{tabular}

Table 2. Results of one-way analysis of covariance in Manco text on mean post-test scores of marital conflict components of women on the verge of divorce of experimental and control group

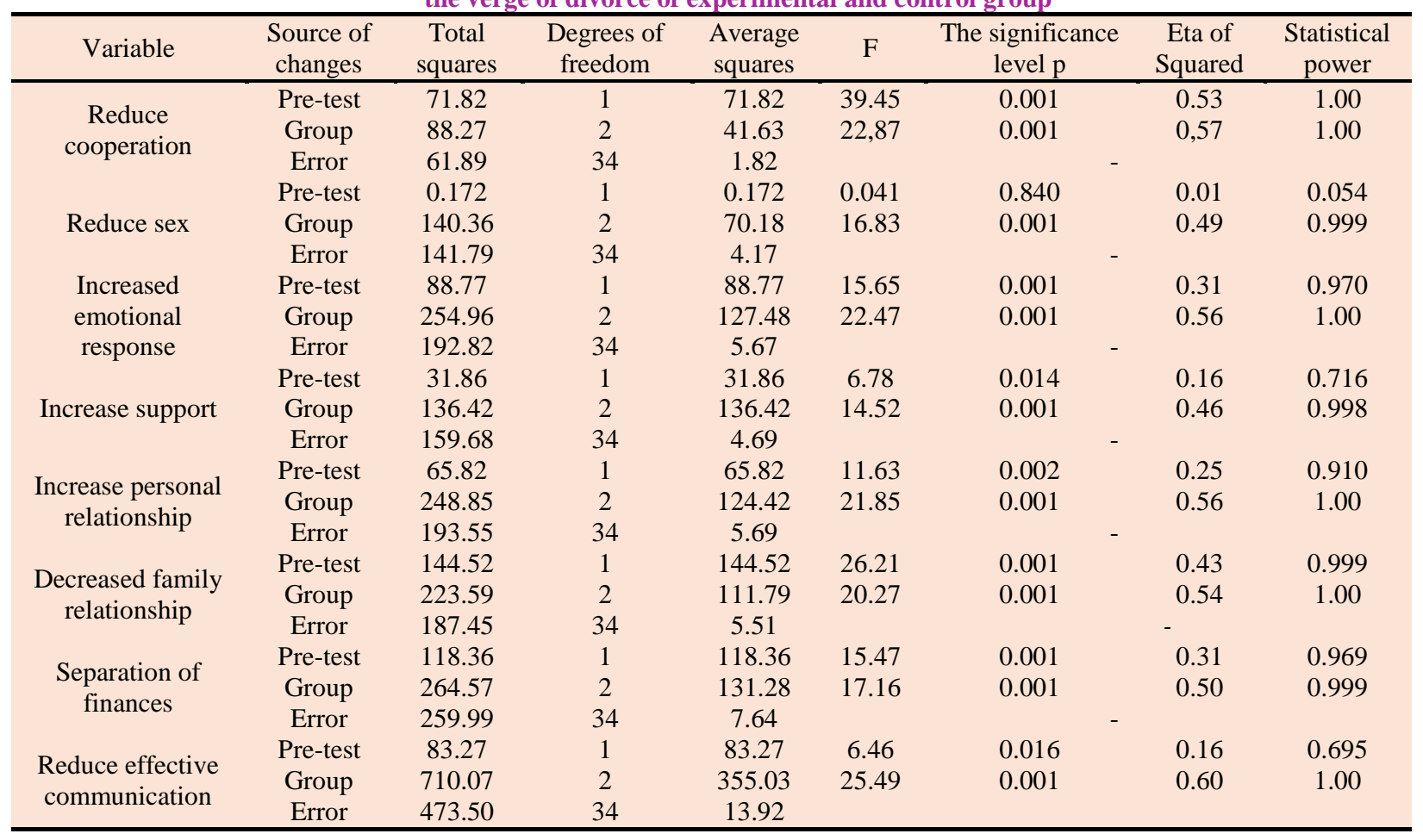




\section{Monthly Journal of Psychological Science}

According to Table 2, there is a significant difference between women on the verge of divorce in the experimental groups and the control group in terms of marital conflict (and all its components).

\section{Conclusion}

The results showed that the use of compassionfocused therapy has significantly reduced the components of marital conflict. Results of this finding with the findings of Neff and Barat Wass (2013); Khalatbari, Hemmati Sabet and Mohammadi (2018); Rajabi et al. (2017) are consistent. Explaining this finding, we can say that people with compassion are able to resolve their interpersonal differences by considering their own and others' desires (Yarnell and Neff, 2013). Self-compassionate people produce positive emotions (Nef and Castigan, 2014) Positive emotions help people to have a high level of communication with their partner and to have a high acceptance of their spouse. Because these emotions expand a person's sense of self in a way that includes others. Over time, this creates a sense of selfotherness or a sense of "unity." The feeling of selfother predicts greater understanding of others, which in turn leads to the development and permanence of interpersonal relationships (Alavi et al., 2016). In the intervention sessions, women were taught to express their feelings. This breaks the cycle of self-absorption and the feeling of loneliness and isolation diminishes and gradually gives way to a feeling of intimacy and connection (Nef, 2012).

The results showed that the use of dialectical behavior therapy has significantly reduced the components of marital conflict. The results of this finding are consistent with the findings of Parizuz, Najarpoorian and Mohammadi (2019), Ghasemabadi et al. (2019) and Harley et al. (2008). Explaining the above result, it can be said that in times of conflict, each spouse seems to have problems in different areas of mindfulness, such as looking at things as they are and not as they are imagined. Mindfulness exercises in DBT affect the mental information processing system by raising people's awareness of the present through focus techniques on breathing, body, and nature (Lee, Bowen, \& Lennarlett, 2005). People try to divert their attention from dysfunctional thoughts and feelings and instead focus more on the body and
Vol. 20, No. 106, Winter(January) 2021

the environment (Bowen et al., 2016); Dortt \& PintoGavia, 2016) and Johnson et al., 2015). In their research, they have reported the effect of mindfulness on interpersonal and marital adjustment. Increasing behavioral skills such as interpersonal skills training and emotional regulation is one of the goals of dialectical therapeutic behavior. From the aspects of married life and marital relationships, it is the emotions experienced by couples that the ability to regulate emotion is very effective in this regard (Liu, Wang and Shi, 2019). In interpersonal ability, individuals learn how to express a need or request without being angry or aggressive, or to respond to the requests and needs of others, and realize that sometimes they can, by saying no and daring, Release themselves from the responsibility of impulsive behaviors (Najjarpoorastadi et al., 1398). People who learn effective communication skills are more likely to be able to reduce their interpersonal differences in a desirable way through effective dialogue, as well as to express a greater sense of empathy for each other (Jafarkhani, Sedghi, \& Shabanian, 2017). One of the limitations of this research is; The use of non-random sampling method, the homogeneity of the sample, the possibility of a halo effect due to both treatments by one person, the lack of follow-up courses, noted.

It is suggested that in future research, the stability of the results be measured using the follow-up test, and also cultural and demographic variables such as immigration, income status, number of children and addiction of the spouse are considered as modifying variables of the research.

\section{Ethical Considerations}

Compliance with ethical guidelines: This article is taken from the $\mathrm{PhD}$ dissertation of the first author in the field of counseling at the Azad University of Ahvaz Branch with the code 10621602972034 and the date of approval of the proposal is 26.06.2019. Also, permits related to research in the statistical community have been issued by the General Department of Welfare of Mazandaran Province.

Funding: This study was conducted as a PhD thesis with no financial support.

Authors' contribution: The first author was the senior author, the second were the supervisors and the third was the advisor.

Conflict of interest: the authors declare no conflict of interest for this study.

Acknowledgments: I would like to appreciate the supervisor, the advisor, Staff of Sari Social Emergency Center. 


\section{مقايسه اثربخشى درمان متمر كزبر شفقت و رفتاردرمانكرى ديالكتيكى بر كاهش تعارض زناشويى زنان در آستانة طلاق}

سيده محبوبه نبوى'، مسعود شهبازى "، امين كرايى"

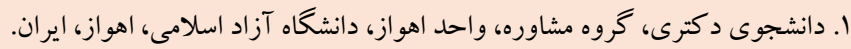

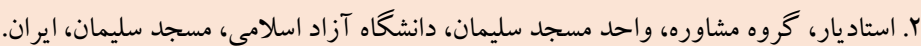

r. استاديار، كروه مشاوره، واحد اهواز، دانشخاه آزاد اسلامى، اهواز، ايران.

جكيان

زمينه: تعارض زناشويى مى تواند بايههاى زندگى مشترك را متزلزل سازد و زمينه طلاق عاطفى و رسمى را فراهم سازد. اثربخشى

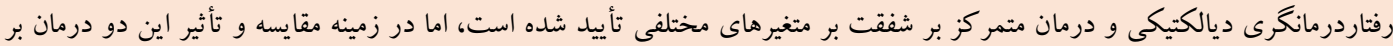
تعارض زناشويى شكاف تحقيقاتى وجود دارد. هدف: هدف يُزوهش حاضر مقايسه اثربخشى آموزش درمان متمركز بر شفقت و رفتاردرمانكرى ديالكتيكى بر كاهش تعارض زناشويى زنان در آستانه طلاق بود.

روش: روش يزوهش به صورت شبه آزمايشى و از نوع بيش آزمون يس آزمون با گروه گ گواه بود. جامعه اين يزوهش را كليه زنان داراى تعارض زناشويى و در آستانهٔ طلاق شهر سارى تشكيل مىدادند كه در سال Vوسا به مراكز مشاوره تحت نظارت سازمان بهزيستى شهرستان

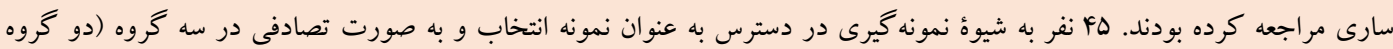

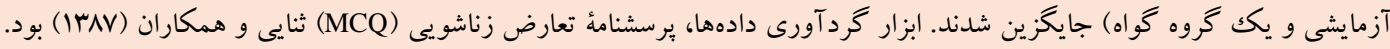

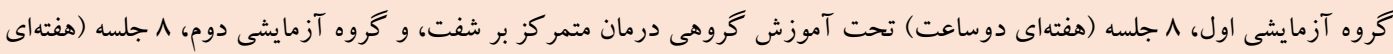

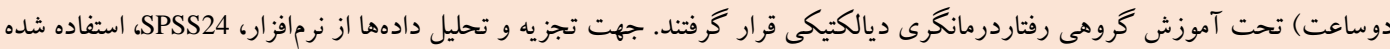
است و دادهها با استفاده از آزمون تحليل كوواريانس جندمتئغيرى تجزيه و تحليل شدند. يافته ها: نتايج نشان داد كه در بِ آزمون، تعارض زناشويى آزمودنىهاى گروههاى آزمايشى نسبت به گروه گو اه، كاهش معنىدارى داشته

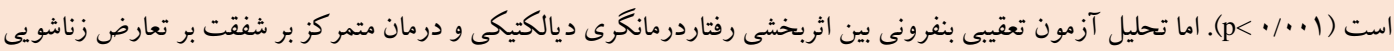
زنان در آستانه طلاق تفاوتى را نشان نداد.

نتيجه كيرى: نتايج اين ئزوهش، حمايت تجربى مناسبى را براى رفتاردرمانكرى ديالكتيكى و درمان متمركز برشفقت فراهم مى آورد.

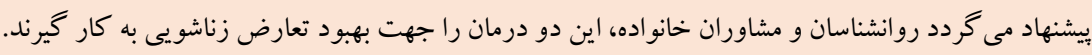

مشخصات مقاله

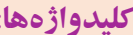

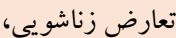
دمان متمر كز بر شفقت،

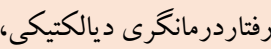

زنان در آستانه طلاق

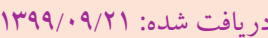

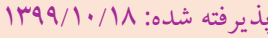

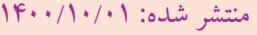

* نويسنده مسئول: مسعود شهبازى، استاديار، گروه مشاوره، واحد مسجد سليمان، دانشكاه آزاد اسلامى، مسجد سليمان، ايران. رايانامة: masoudshahbazi66@yahoo.com 
خودكشى، از جمله آثار منفى طلاق براى زوجين و به خصوص زنان است

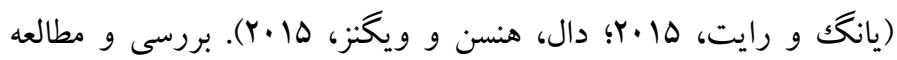

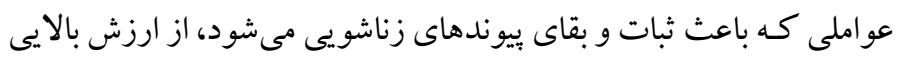
برخوردار است. از همين روى، شناسايى انواع شيوهاى مداخلهاى كار آمد جهت كاستن تعارض و نارضايتى زناشويى مى تواند قدم مهمى در جهت

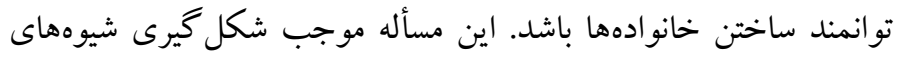
درمانى متعددى شده كه هدف آنها ارائه نوعى خدمات روانشناختى به

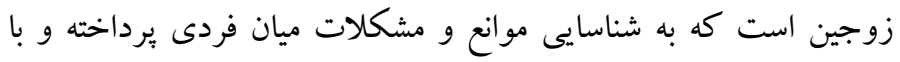
آموزش شيوه مناسب حل مسئله و الكوى رفتارى مناسب، به شكل مئل

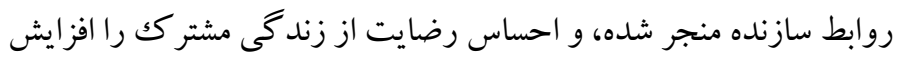
مىدهند (نولند، جورجيا و داس، IV). يكى از شيوههاى درمانى كه اثربخشى آن در زمينههاى مختلفى از جمله؛

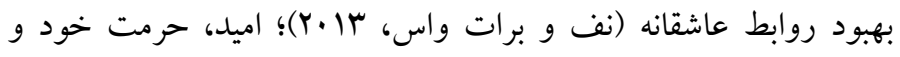

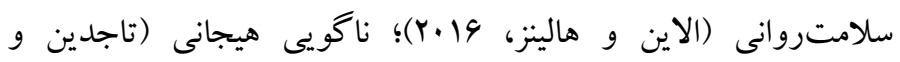

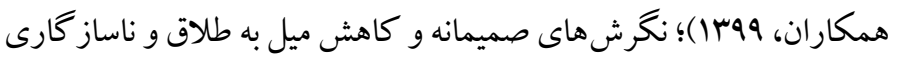

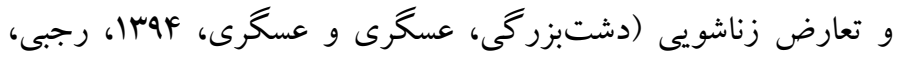

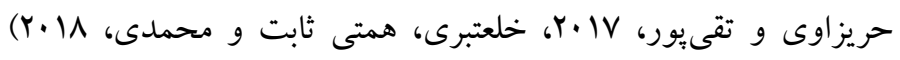

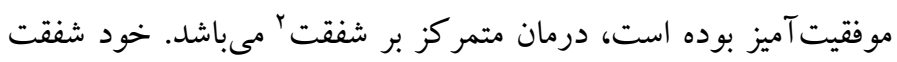

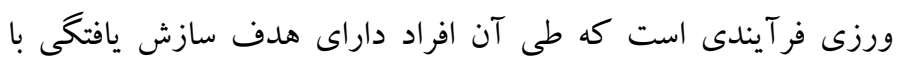
مشكلات بوده و ذهنيتى دلسوزانه نسبت به خود اتخاذ مى كنند و مستلزم سازش يافتخى فعالانه، يذيرش كاستىها و هشيارى نسبت به ونه افكار،

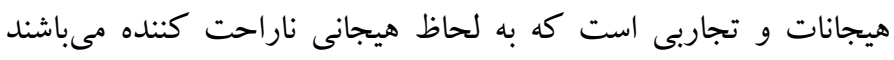

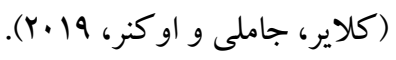
شفقت به خود داراى سه جنبه است: مهربان بودن با خود در برابر قضاوت

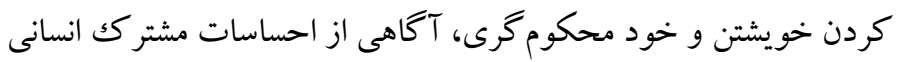
در برابر حس تنهايى و شرم، هوشيارى در برابر همانندسازى فز آينده (وجى،

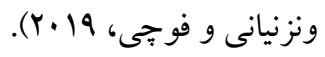
شفقتورزى به اين اصل مهم تاكيد مى كند كه تصويرها، افكار، تجارب و و ونه رفتارهاى آرامشبخش بيرونى و خارجى بايد درونى شوند؛ بدين ترتيب، ذهن شخص همانطور كه نسبت به مسائل بيرونى و خارجى عكسى العمل نشان مىدهد، در برخورد با اين درونيات خويشتن هم آرام شود (گيلبرت،

2 . Compassion Focused Therapy
مقام برقرارى ارتباط صميمانه، يكى از كشاكشهاى عاطفى مهم در زندگى

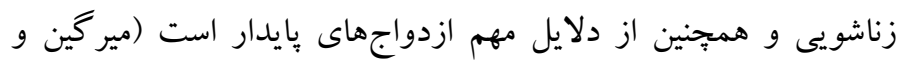

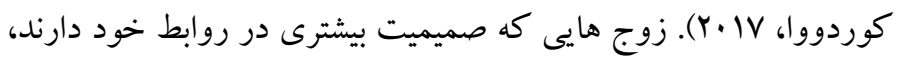
مىتواند خود را به روش بهترى عرضه و خواستهاى خود را به نحو

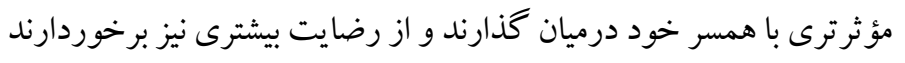

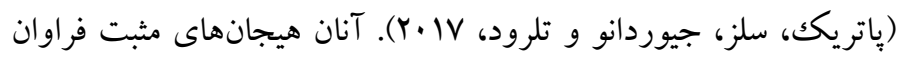
ترى را تجربه مى كنند و از كذشته خود و اطرافيان، تجارب مثبت بيشترى ترودي

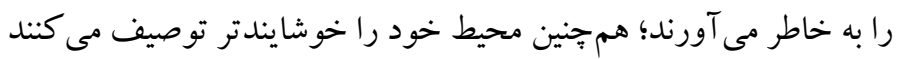
(ويليامسون و لاونر، 19 19). عوامل متعددى روابط زناشويى زوجين را تهديد مى كند و سبب فرسايش عشق و صميميت ميان آنان مىشود

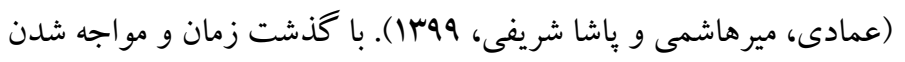

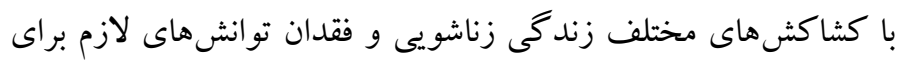
بهبود كيفيت رابطهُ زناشويى، به تدريج زوجين دجار تعارض ' مىشوند

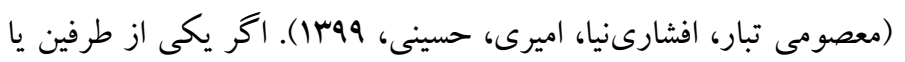

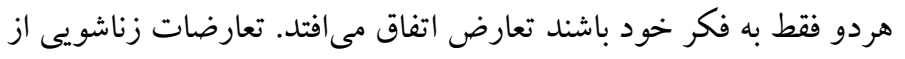

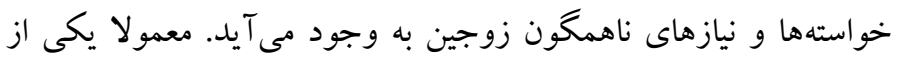

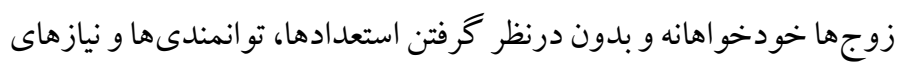

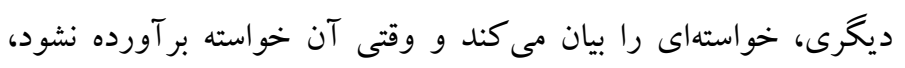
تعارض ايجاد مىشود (ويلسون و همكاران، IV. IV).

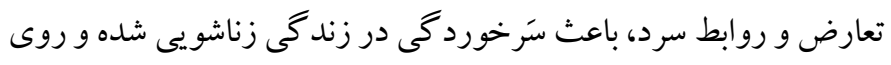
ساير نقشها منجمله نقش والدينى و نقش شغلى مؤثر است (مينوت،

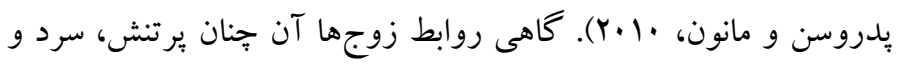
غيرقابل تحمل مىشود كه راه جارهاى جز طلاق باقى نمىماند (رضايى،

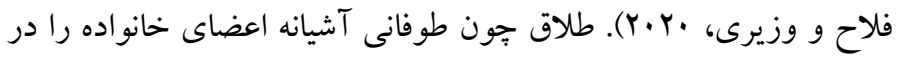
هم مى كوبد، و خصو صا زنان را به دليل دارا بودن موقعيت و سرشت خاص

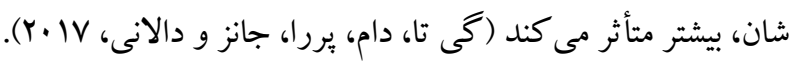

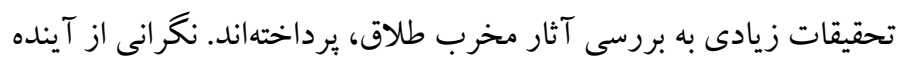

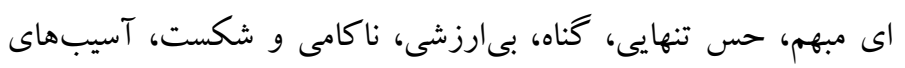
جسمى و عاطفى، انحر افات جنسى، فحشا، مشكلات اقتصادى، منزوى شدن

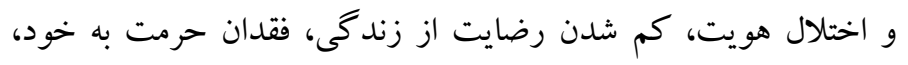




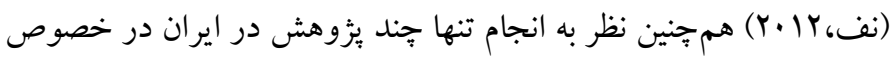

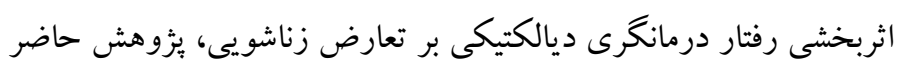

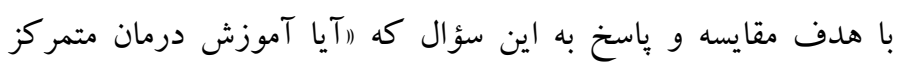

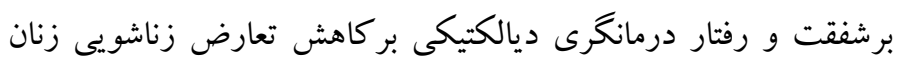

مؤثر است؟ा).

روش

الف) طرح بثزوهش و شركت كنند كان: اين يزوهش، مطالعهاى شبه

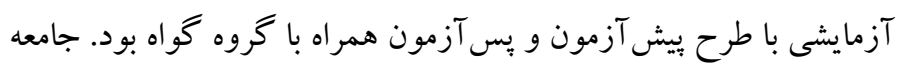

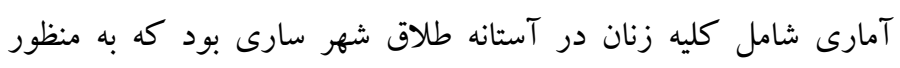

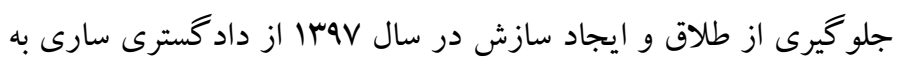

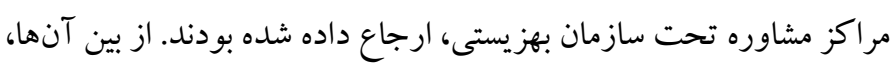

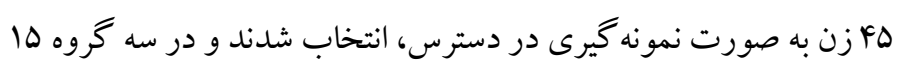

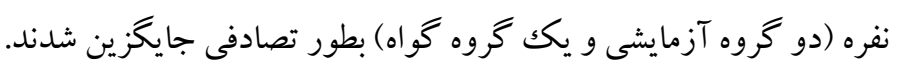

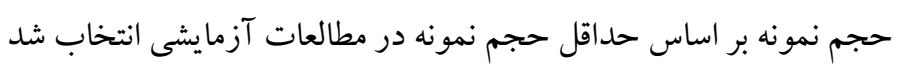

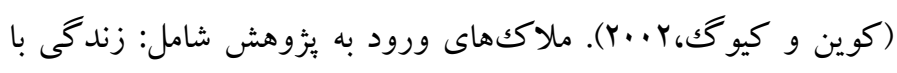

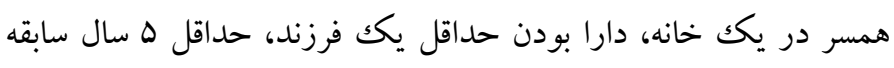

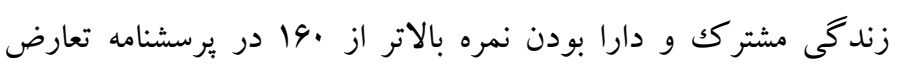

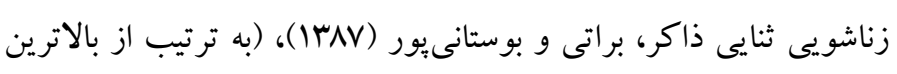

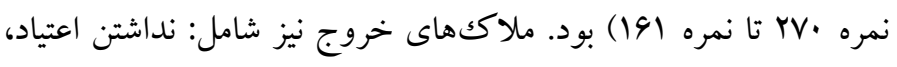

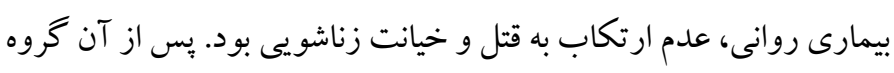

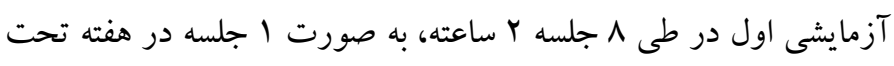
آموزش گروهى درمان متمر كز برشفقت قرار گرفت. گروه آز آزمايشى دوم

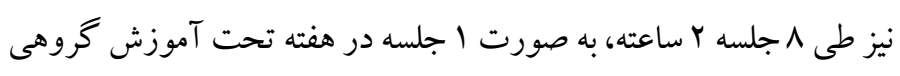
رفتاردرمانكرى ديالكتيكى قرار خرفت.

محتواى جلسات درمان مبتنى بر شفقت (جدول ())، بر اساس كتابهرداى

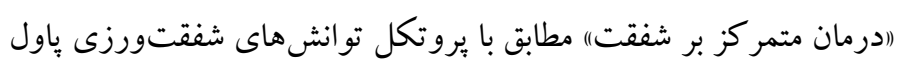

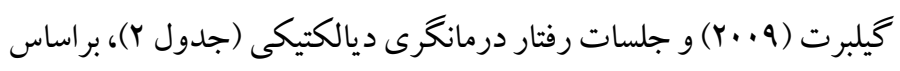

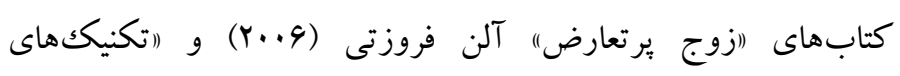

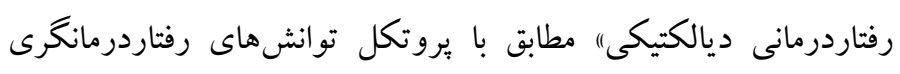

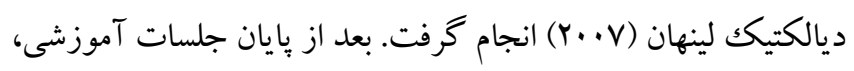

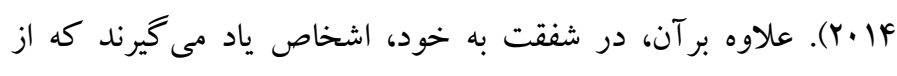

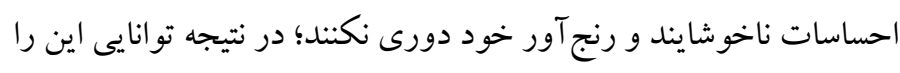
بيدا مى كنند كه از تجربه خود آكاهى يابند و احساس شفقت نسبت به آن نان

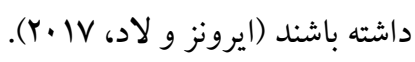

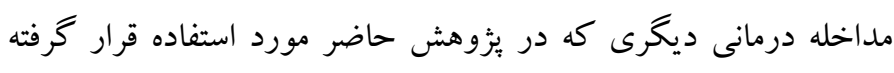

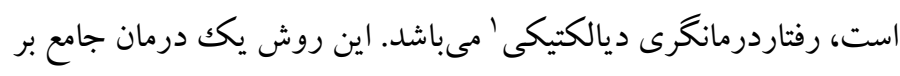

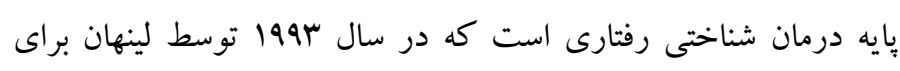

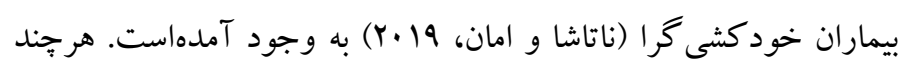
روش درمانكرى ديالكتيكى معيارطلايى براى درمان اختلال شخصيت

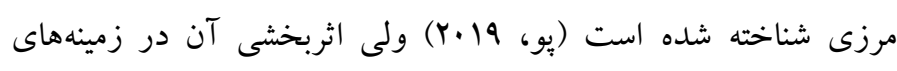

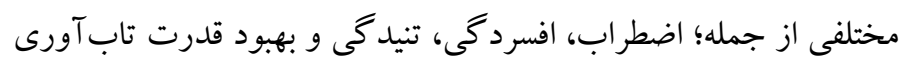

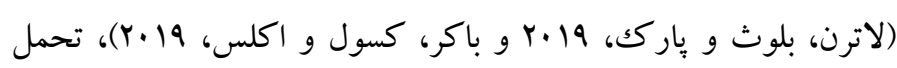
درماند گى، خودنظم جويى، كاهش هيجانهاى منفى (رابينسون و همكاران،

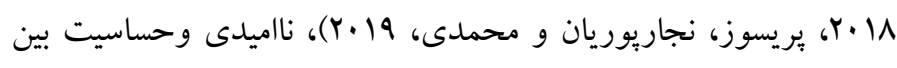

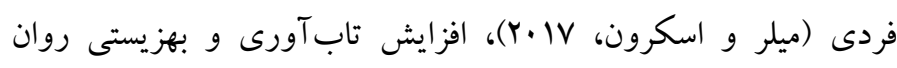

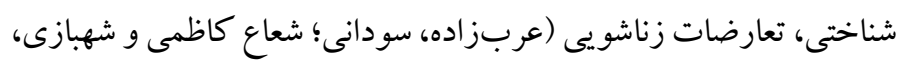

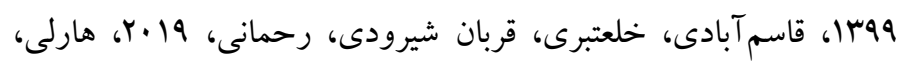

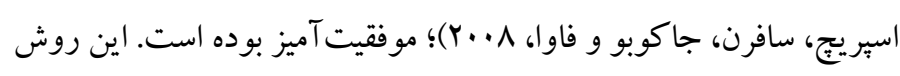
براى افر ادى كه قصد كنترل هيجانهاى آشفتهساز را دارند، بسيار اثربخش ونش

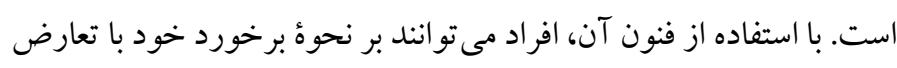

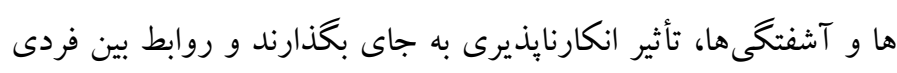

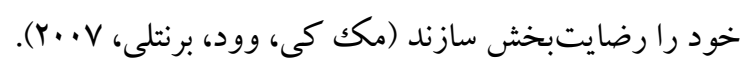

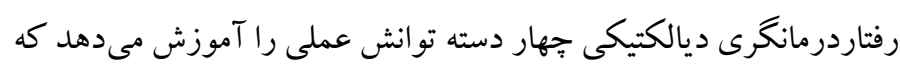

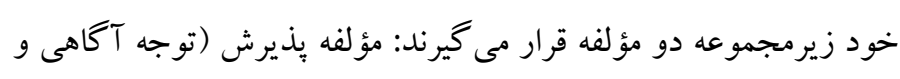

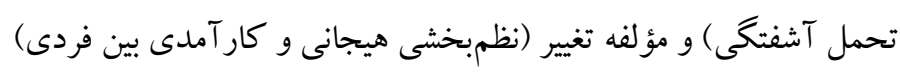

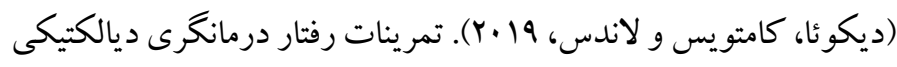

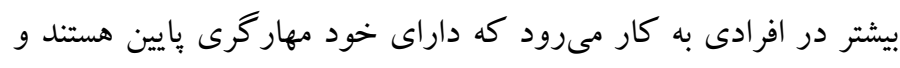

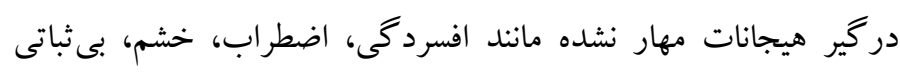
عاطفى و تحريكك يذيرى در گير هستند (قدرتى تربتى، نجات، توزنده جانى،

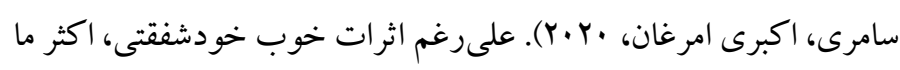
در فرهنگكايى زندگى مى كنيم كه بر خودشفقتى تأكيد نمى كند آند

1. Dialectical Behavior Therapy 
مجدداً يرسشنامه ذكر شده در مورد هر گروه به عنوان بِ آزمون اجرا شد دادههاى جمع آورى شده در نهايت مورد تجزيه و تحليل قرار گرفت.

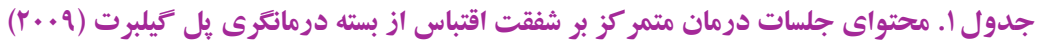

\begin{tabular}{|c|c|c|}
\hline 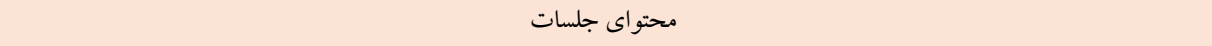 & 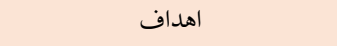 & جلسات \\
\hline آشنايى مختصر با اصول اين درمان، بيان تفاوت شفقت به خود با تأسف براى خود؛ مفهومسازى آموزش خودشفقتى؛ تعريف شفقت & آشنايى با مفهوم شفقت به خود & اول \\
\hline توضيح در مورد سه سيستم تنظيم هيجان و نحوه تأثير گذارى آن بر شخص، بيان تمايز ميان ذهن مشفق و ذهن مبتنى بر تهلديد. & معرفى سيستمهاى تنظيم هيجان & دوم \\
\hline آكاهى و شناخت مغز قديم، جديد و آكاه. آشنايى با توانشهاى ذهن آكاهى به همراه تمرين تنفس تسكينبخش و وارسى بدنى & آشنايع با مغز قديم، جديد و آكاه & سوم \\
\hline معرفى خصوصيات ششكانه مفهوم شفقت (بعد التيام)، شناخت انسان مشفق و اشاره به ويزگ گیىاى آن & شناخت فرد مشفق & جهارم \\
\hline آموزش روش تصويريردازى خودِ مشفق و تجسم بهترين حالت خود & استلال مشفقانه و توجه مشفقانه & ينجم \\
\hline 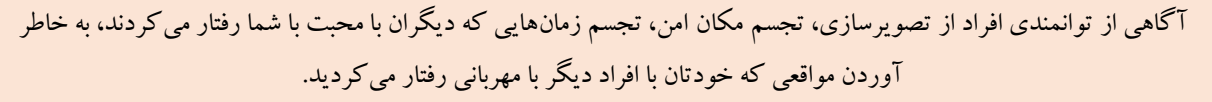 & تصويرسازى و تجربه حسى مشفقانه & ششم \\
\hline تمرين مهربانى و شفقت به خود و تحول و يرورش شفقت درونى. تمرين روشهاى مختلف ابراز شفقت & احساس مشفقانه & هفتم \\
\hline 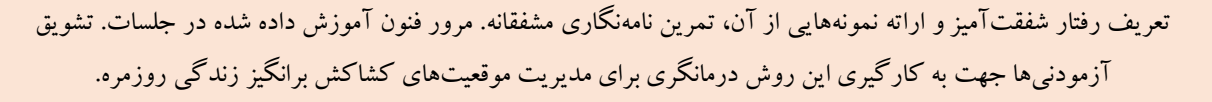 & رفتار مشفقانه ارزيابى و كاربرد & هشتم \\
\hline
\end{tabular}

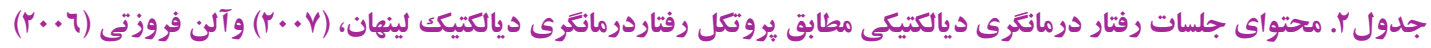

\begin{tabular}{|c|c|c|}
\hline محتواى جلسات & اهداف & جلسات \\
\hline تعريف ديالكتيك و معرفى كلى رفتاردرمانگرى ديالكتيكى، آشنايى با مفهوم ذهن آكاهى & تعريف ديالكتيك و ذهن آكاهى & اول اول \\
\hline 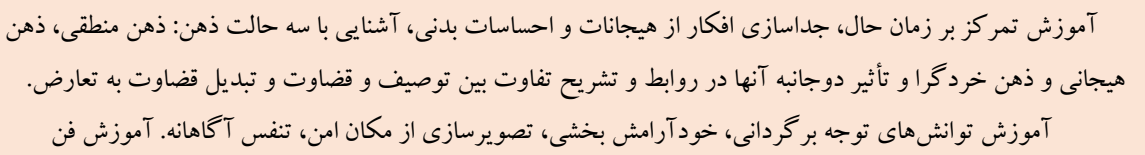 & آموزش توانشهاى ذهن آكاهى & 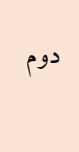 \\
\hline 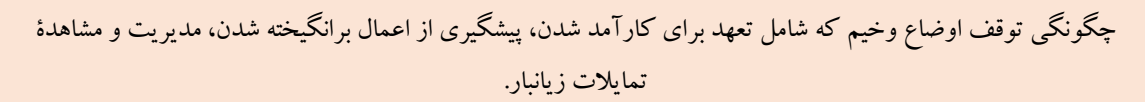 & آموزش توانشهاى تحمل آشفتگى & 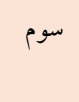 \\
\hline تدوين طرح تنشزدايى، تحمل آشفتخى با استفاده از افكار مقابلهاى خود تشويق گر ايانه، و خود گويىهاى تأيدگرا ايانه. & آموزش توانشهاى تحمل آشفتخى & جهارم \\
\hline 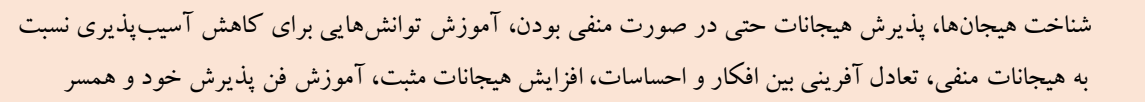 & آموزش توانشهاى تنظيم هيجان & ينجم \\
\hline 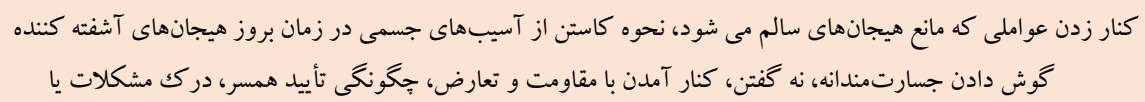 & آموزش توانشهاى تنظيم هيجان & ششم \\
\hline اشتباهات همسر، آموزش فن ابراز روشن احساسات شامل: شناسايى خو استها و احساسات مبهم، استفاده از ارتباطات & آموزش توانشهاى ارتباط مؤثر & 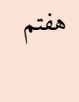 \\
\hline 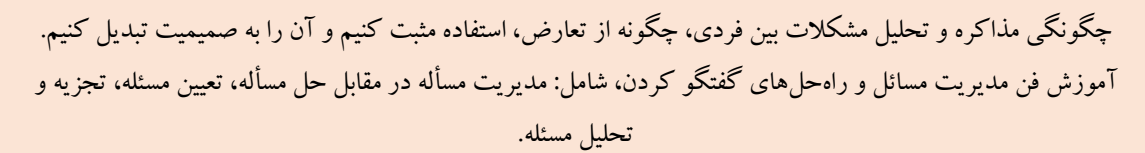 & آموزش تو انشهاى ارتباط مؤثر & 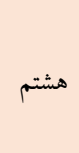 \\
\hline
\end{tabular}

تداوم همكارى خود در طى جلسات در هر مقطعى آزاد هستند. همجنين در صورت تمايل جهت دريافت و بررسى نتايج آزمون يكك جلسه مشاوره رايگان براى هر يكك از آنها در نظر گرفته شد.

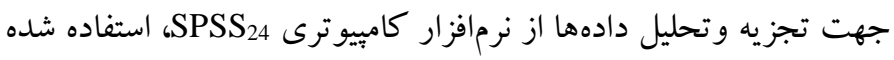

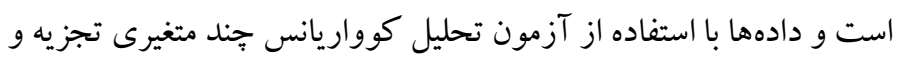

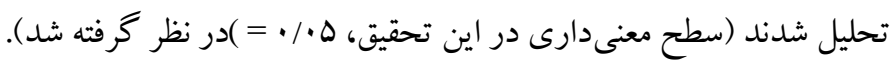

با توجه به لزوم رعايت اصول اخلاقى در تحقيق، در مورد رازدارى و محرمانه بودن اطلاعات كسب شده از اعضاء، به آنان اطمينان داده شد كه له تنها براى يزوهش حاضر از اين اطلاعات استفاده خواهد شد، بنابراين هيج

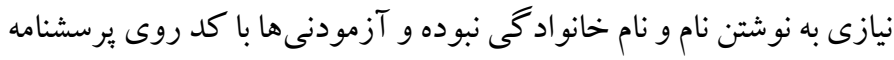

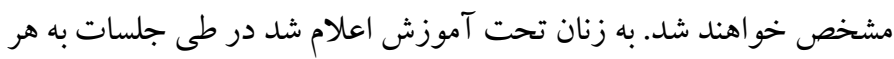

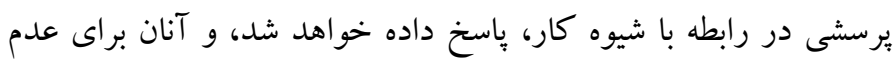


يكديخر، س//•؛ كاهش ارتباط مؤثر، VA/•؛ مى باشد كه بيانگر ضرايب

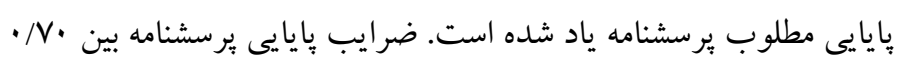
تا سوه/• نوسان دارد.

يافته ها

يافتهاى حاصل از دادهاى جمعيت شناختى نشان داد كه زنان نمونه

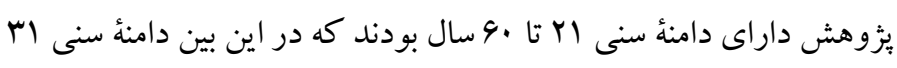

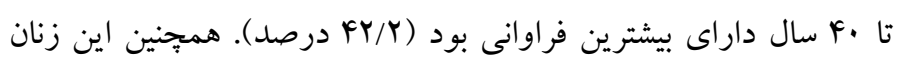
داراى سطح تحصيلات زيرديبلم تا فوق ليسانس بودند كه سطح دييلم تا بـ

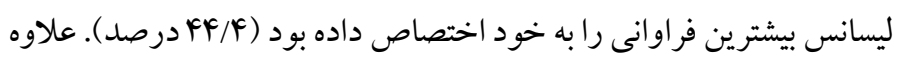

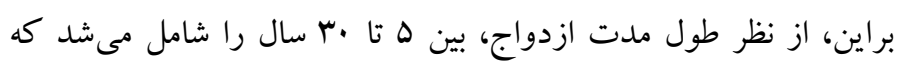

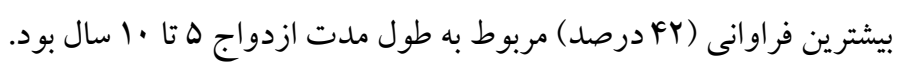
يافتهاى توصيفى اين بثزوهش شامل شاخص هاى آمارى مانند ميانخين،

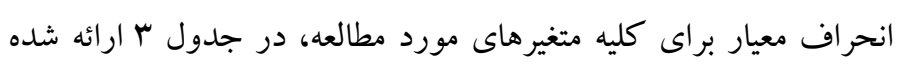

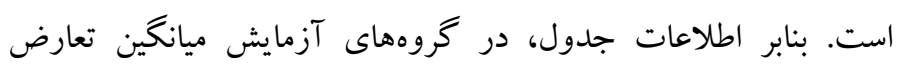
زناشويى و مؤلفههاى آن درمر حله بس آزمون در قياس با مرحله بيش آزمون

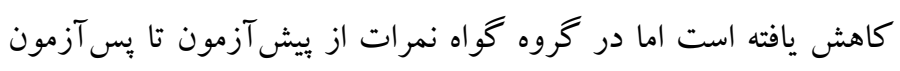
تغيير جندانى ندارند.
ب) ب ب ابزار

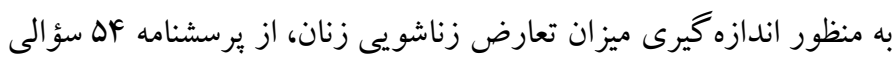
تعارض زناشويى (MCQ) ثنايى ذاكر، براتى و بوستانى يور (IrAV) )، استفاده شده است كه 1 مؤلفهُ كاهش همكارى، كاهش رابطه جنسى، افزايش

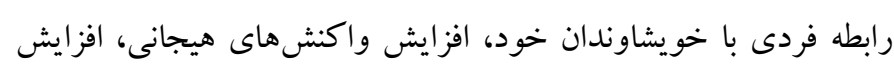

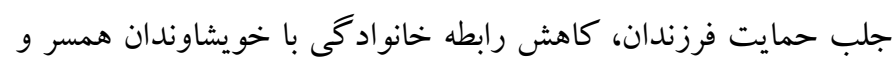

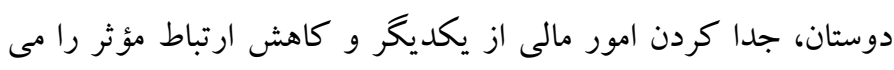

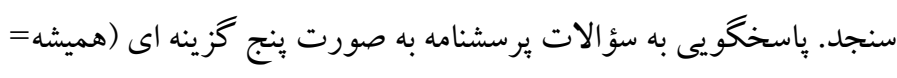

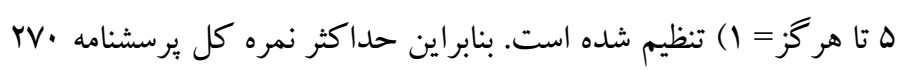

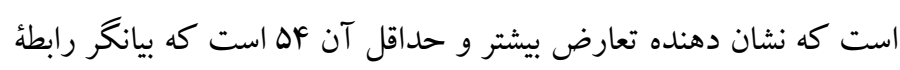

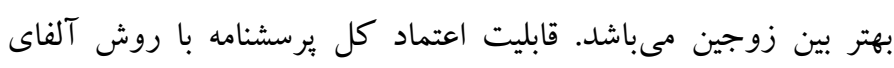

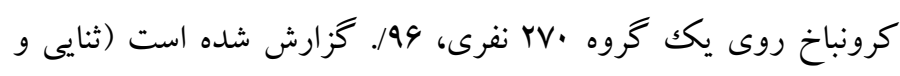

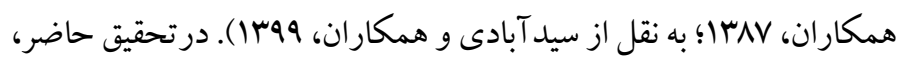

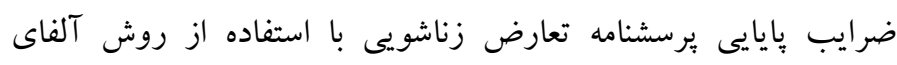

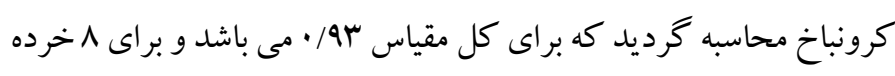

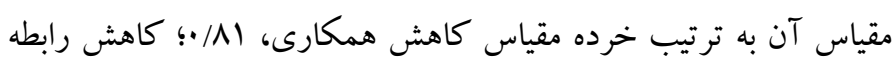

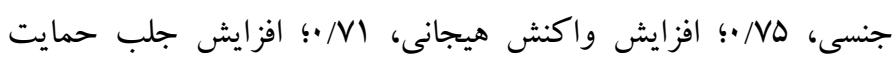

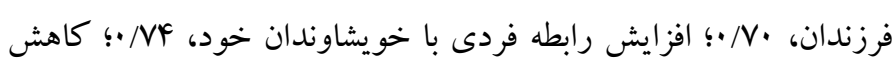

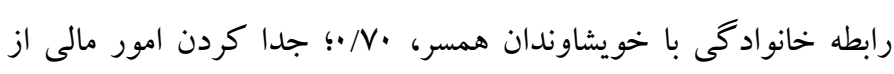

\begin{tabular}{|c|c|c|c|c|c|}
\hline انحر اف معيار & ميانخين & شاخص آمارى & كرو & مرحله & متغير \\
\hline IT.VV & MA.Dr & رفتاردرمانكرى ديالكتيكى & & & \multirow{6}{*}{ نعارض زناشويى } \\
\hline r1. 99 & $M M . V$ & درمان متمركز بر شفقت & & ي بيش آزمون & \\
\hline $11 . .9$ & ING.F. & كواه & & & \\
\hline $11 . \wedge$. & irr.rr & رفتار درمانكرى ديالكتيكى & & & \\
\hline $1 F . F 9$ & IrD.qr & درمان متمركز بر شفقت & & يس آزمون & \\
\hline IF.rA & int.ir & كواه & & & \\
\hline
\end{tabular}

همخطى جند گانه بين متغيرهاى كمكى (كوواريتها)، تأييد شده است. و

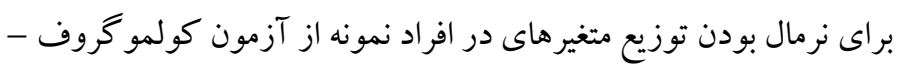

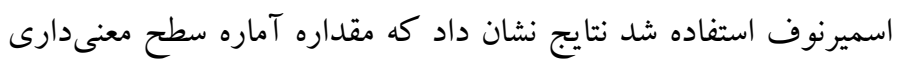

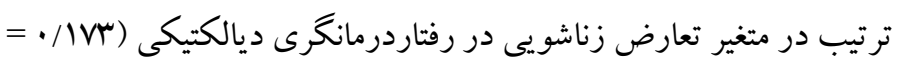

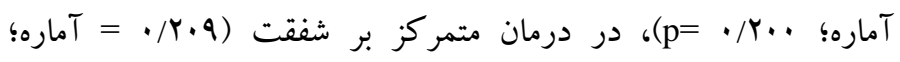

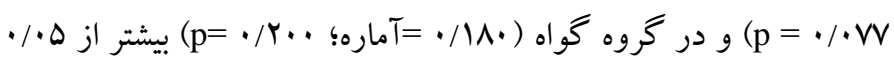

براى بررسى معنىدارى تغييرات از آزمون تحليل كوواريانس استفاده شد.

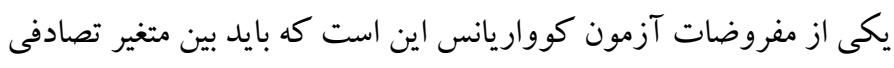

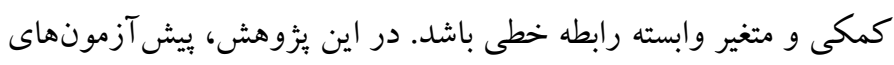

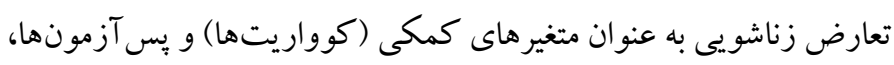

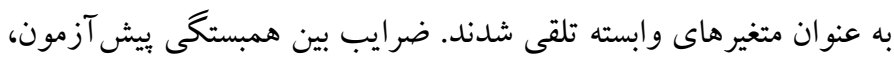

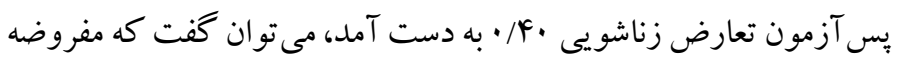


متغيرها تعامل بين گروه (آزمايش و گو اه) بإِيش آزمون بررسى شد با توجه

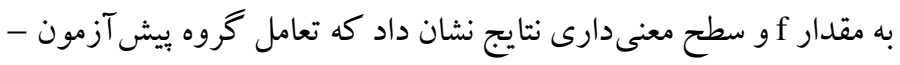

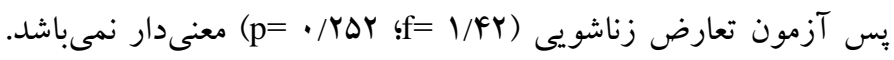

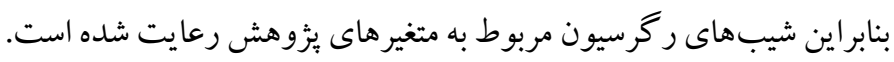

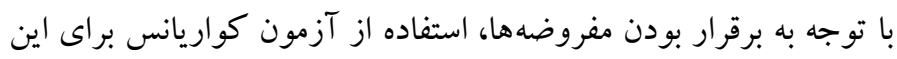
ئزوهش بلامانع مىباشد.
صدم بود بنابراين توزيع متغير نرمال است لذا اين ييشفرض هم رعايت

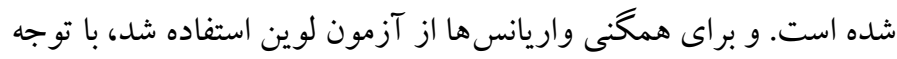

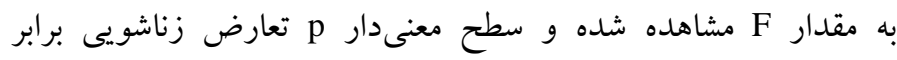

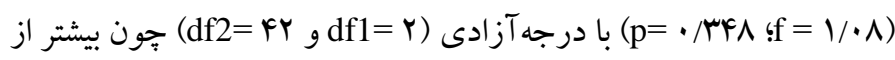

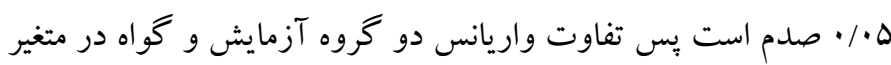

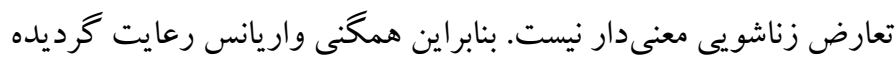

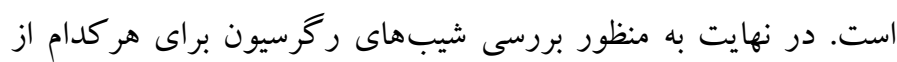

\begin{tabular}{|c|c|c|c|c|c|c|c|c|}
\hline توان آمارى & مجذور اتا & سطح معنى دارى p & $\mathrm{F}$ & ميانگين مجذورات & درجه آزادى & مجموع مجذورات & منبع تغييرات & متغير \\
\hline $1 / \cdot$ & $\cdot / \Delta r$ & $\cdot / \cdot \cdot 1$ & $F \Delta / F V$ & rVFN/Aq & 1 & TVFN/Aq & ييش آزمون & \\
\hline \multirow[t]{2}{*}{$1 / \cdot$} & $\cdot / A r$ & $\cdot / \cdot 1$ & $a r / V I$ & $V G F F / Y$. & r & $|O r M M / F|$ & كروه & تعارض زناشويى \\
\hline & & - & & $\Lambda Y / F F$ & f. & rrqV/A. & خطا & \\
\hline
\end{tabular}

متمر كز بر شفقت (عضويت گروهى) مىباشد. توان آمارى برابر با ../ است، به عبارت ديخر، امكان خطاى نوع دوم وجود نداشته است. معنى دار

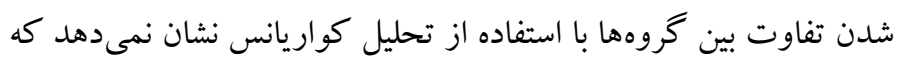

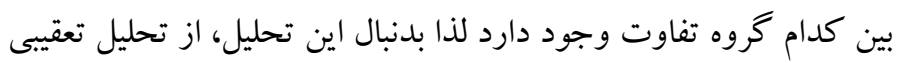
بونفرونى استفاده شد كه نتايج آن در جدول ها ارائه شده است.
همان طور كه در جدول F مشاهده مىشود بين زنان در آستانه طلاق گروه

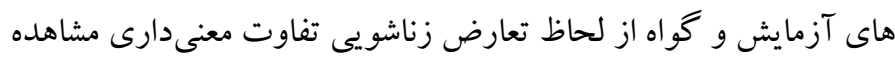

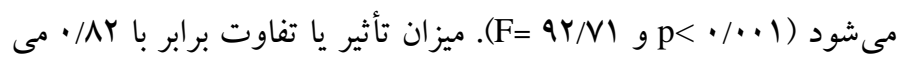
باشد، به عبارت ديخر، به درصد تفاوتهاى فردى در نمرات بـ بـ آزمون

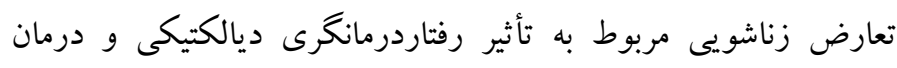

جدول ه. نتايج آزمون تعقيبى بونفرونى بين نمرات ميانعين يس آزمون تقارض زناشويى كروههاى آزمايش و كواه

\begin{tabular}{|c|c|c|c|c|}
\hline كواه & درمان متمركز بر شفتت & رفتاردرمانغرى ديالكتيكى & ميانگين & كروه ها \\
\hline$(\mathrm{p}=\cdot / \cdot \cdot 1) *$ & NS $(p=\cdot / ৭ 99)$ & - & r & درمان (DBT) \\
\hline \multirow[t]{2}{*}{$(\mathrm{p}=\cdot / \cdot \cdot 1) *$} & - & - & rrda/q & درمان (CFT) \\
\hline & - & - & IVr/Ir & كو اه \\
\hline
\end{tabular}

وجود ندارد (p=/999) • اين امر بيانخر تأثير تقريباً يكسان رفتار درمانكرى

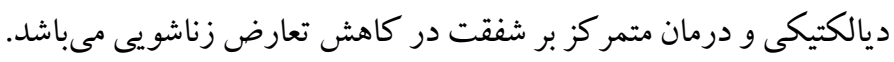

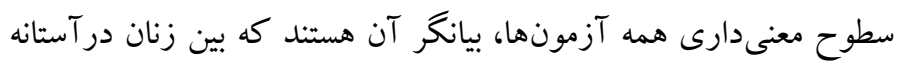

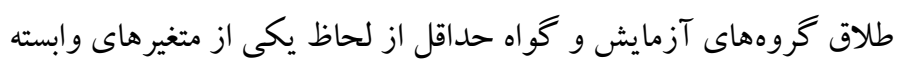

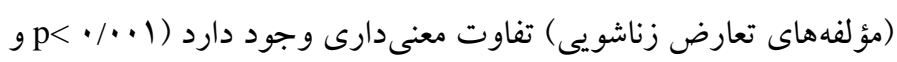

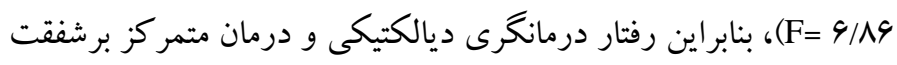

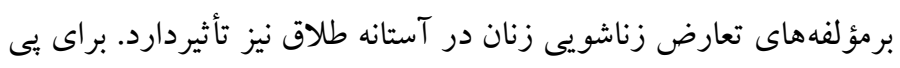

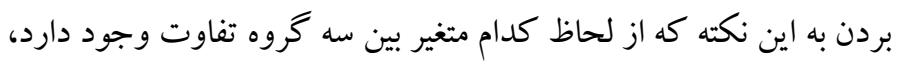
هشت تحليل كواريانس يككراهه در متن مانكوا انجام گرفت كه نتايج حاصل در جدول V نشان داده شده است. ميزان تأثير يا تفاوت برابر با لو 19V.
با توجه به جدول ه، بين ميانگين پِ بس آزمون تعارض زناشويى زنان در

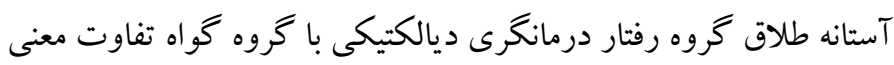

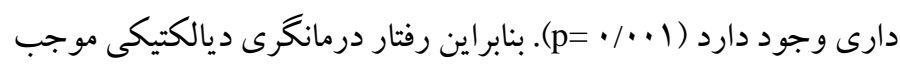

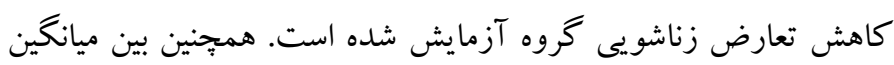

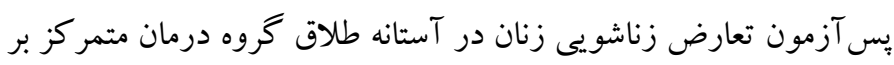

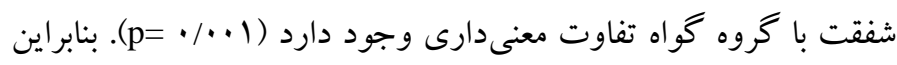
درمان متمركز برشفقت موجب كاهش تعارض زناشويى گروه آزمايش

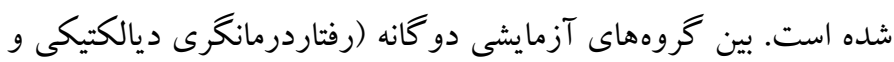
درمان متمركز برشفقت) از لحاظ تعارض زناشويى تفاوت معنىدارى 
با توجه به جـدول V، بين زنان در آستانه طلاق گروههاى آزمايش و گروه

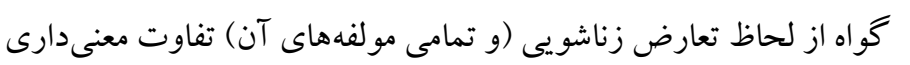

$$
\text { مشاهده مى شود. }
$$

مىباشد، به عبارت ديخر، 9V درصد تفاوتهاى فردى در نمرات بِ

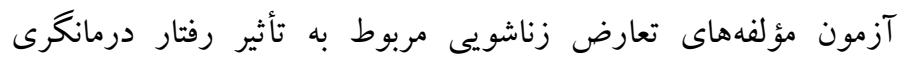

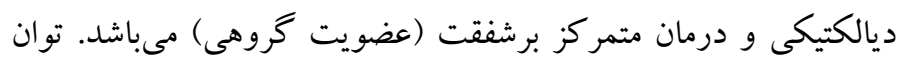

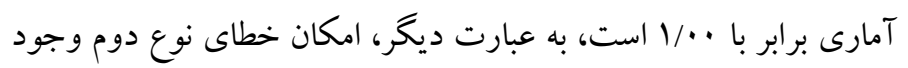
نداشته است.

\begin{tabular}{|c|c|c|c|c|c|c|c|}
\hline توان آمارى & مجذور اتا & سطح معنى دارى (p) & $\mathrm{F}$ & خط DF & Dر DF & مقدار & نام آزمون \\
\hline $1 / \cdot \cdot$ & $\cdot / \Delta F$ & $\cdot \cdots \Delta$ & $F / I r$ & $\Delta 4$ & 19 & $1 / \cdot 1$ & آزمون اثر ييلايى \\
\hline $1 / \cdot$ & $\cdot 19 \mathrm{~V}$ & $\cdot / \cdots 1$ & 9/19 & $\Delta F$ & 19 & 1.9 & آزمون لامبداى ويلكز \\
\hline $1 / \cdot$ & ./V9 &.$/ \cdot 1$ & $1 . / 49$ & $\Delta r$ & 19 & $9 / 4 F$ & آزمون اثر هتلينك \\
\hline $1 / \cdot$ & $\cdot / \wedge 9$ &.$/ .1$ & $r M / Q F$ & ru & $\wedge$ & $9 / 10$ & آزمون بزر گترين ريشه روى \\
\hline
\end{tabular}

جدول V. نتايج تحليل كواريانس يككراهه در متن مانكوا روى ميانتَين نمرات يس آزمون مؤلفهاى تعارض زناشويى زنان در آستانه طلاق كروههاى آزمايش و كواه

\begin{tabular}{|c|c|c|c|c|c|c|c|c|}
\hline توان آمارى & مجذور اتا & pطح معنى دارى p & $\mathrm{F}$ & ميانگين مجذورات & درجه آزادى & مجموع مجذورات & منبع تغييرات & متغير \\
\hline $1 / \cdot$ & $\cdot / \Delta r$ &.$/ \cdot 1$ & $r q / F \Delta$ & VI/Ar & 1 & $V Y / A r$ & ييش آزمون & \multirow{3}{*}{ كماهش } \\
\hline \multirow[t]{2}{*}{$1 / \cdot$} & \multirow[t]{2}{*}{$\cdot / \Delta V$} & \multirow[t]{2}{*}{.$/ \cdot 1$} & \multirow[t]{2}{*}{ Yr/AV } & $41 / 94$ & r & $M N / T V$ & كروه & \\
\hline & & & & I/Ar & MF & $91 / 19$ & خطا & \\
\hline.$/ \Delta F$ &.$/ \cdot 1$ & - /AF. & $.1 .+4$ & $\cdot / \mathrm{Vr}$ & 1 &.$/$ IVT & يَيش آزمون & \multirow{3}{*}{ كاهش رابطه } \\
\hline \multirow[t]{2}{*}{.$/ 999$} & \multirow[t]{2}{*}{$\cdot / 4 q$} & \multirow[t]{2}{*}{.$/ . .1$} & \multirow[t]{2}{*}{ IS/Ar } & $v \cdot / 11$ & r & $14 \cdot / 49$ & كروه & \\
\hline & & & & $F / I V$ & re & $|f| / v q$ & خطا & \\
\hline $.9 v$ & $\cdot \pi$ & $\cdot / \cdot 1$ & $10 / 90$ & $M / V V$ & 1 & MN/V & يِش آزمون & \multirow{3}{*}{ فز ايش واكنش } \\
\hline \multirow[t]{2}{*}{$1 / \cdot$} & \multirow[t]{2}{*}{$\cdot / 09$} & \multirow[t]{2}{*}{.$/ . \cdot 1$} & \multirow[t]{2}{*}{$Y Y / F V$} & ITV/FA & r & YOF/QQ & كروه & \\
\hline & & & & $\Delta / 9 V$ & rF & IQY/A9 & خطا & \\
\hline$\cdot / \mathrm{V} \backslash 9$ &. .19 &.$/ \cdot 1 f$ & $9 / \mathrm{VA}$ & M/A9 & 1 & $r 1 / \Lambda 9$ & ييش آزمون & \multirow{3}{*}{ افزايش جلب } \\
\hline \multirow[t]{2}{*}{.$/ 991$} & \multirow[t]{2}{*}{. .49} & \multirow[t]{2}{*}{$\cdot / \cdot .1$} & \multirow[t]{2}{*}{$\mid F / \Delta r$} & IrG/Fr & r & IrG/FY & كروه & \\
\hline & & & & $r / 99$ & re & $109 / 91$ & خطا & \\
\hline.$/ 91$. & $\cdot / r \Delta$ & $\because \cdot r$ & $11 / 94$ & 9D/Ar & 1 & $9 D / A r$ & يِيش آزمون & \multirow{3}{*}{ افز ايش رابطه } \\
\hline \multirow[t]{2}{*}{$1 / \cdot$} & \multirow[t]{2}{*}{$\cdot / 09$} & \multirow[t]{2}{*}{.$/ \cdot 1$} & \multirow[t]{2}{*}{$r M / \wedge \Delta$} & $\mid Y F / F Y$ & r & YFA/AD & كروه & \\
\hline & & & & $8 / 99$ & $r F$ & $19 r / \Delta \Delta$ & خطا & \\
\hline.$/ 999$ & . & $\cdot / \cdot \cdot 1$ & $r q / r)$ & $\mid F F / \Delta Y$ & 1 & $\mid F F / \Delta Y$ & يِيش آزمون & \multirow{3}{*}{ خاهش رابطه } \\
\hline \multirow[t]{2}{*}{$1 / \cdot \cdot$} & \multirow[t]{2}{*}{$\cdot / \Delta F$} & \multirow[t]{2}{*}{.$/ .1$} & \multirow[t]{2}{*}{$r \cdot / T V$} & $111 / 29$ & r & TrM/DQ & كروه & \\
\hline & & & & $\Delta / \Delta 1$ & rF & $\mid A V / F \Delta$ & خطا & \\
\hline.$/ 999$ & $\cdot / \Gamma 1$ & $\cdot / \cdot .1$ & $\mid \Delta / F V$ & $111 / 49$ & 1 & $111 / r_{9}$ & ييش آزمون & \\
\hline \multirow[t]{2}{*}{.$/ 999$} & \multirow[t]{2}{*}{$\cdot / \Delta$} & $\cdot / \cdot .1$ & $1 V / 19$ & ATI/YA & r & YGF/OV & كروه & \\
\hline & & & & $V / q 4$ & $r F$ & $r \Delta Q / Q q$ & خطا & لموركس \\
\hline .1990 &.$/ 19$ &.$/ .19$ & $9 / 49$ & $\Lambda \Gamma / Y v$ & 1 & $\Lambda T / Y V$ & بيش آزمون & \\
\hline $1 /$. & .19 & $\cdot / \cdot .1$ & $r \Delta / \& q$ & $r \Delta \Delta / \cdot r$ & r & $v 1 \cdot / \cdot v$ & كروه & \\
\hline & & & & $1 r / q r$ & rF & $F V Y / \Delta$. & خطا & \\
\hline
\end{tabular}


زيرا اين هيجانات، احساس شخص از خودش را طورى گسترش مى مهد

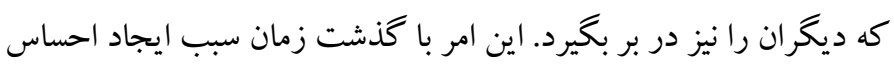

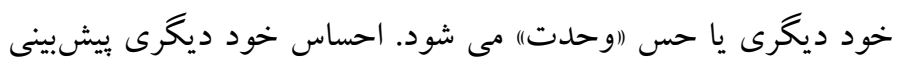

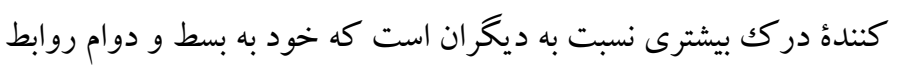

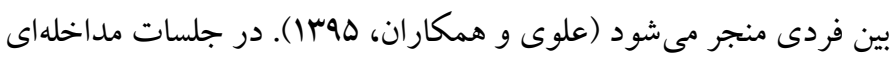

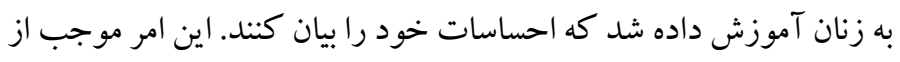

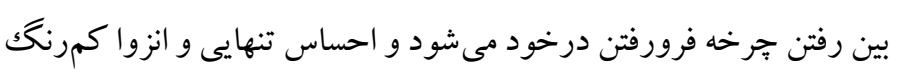
تر شده و به تدريج و جاى خود را به احساس صميميت و بيوند مى بـدهد

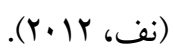

يافته ها نشان داد كه به كار گيرى رفتاردرمانگرى ديالكتيكى موجب كاهش معنى دار مؤلفه هاى تعارض زناشويى شده است. نتايج اين يافته با يافته هاى

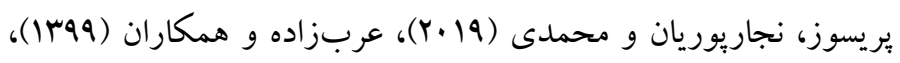
قاسم آبادى و همكاران (Y.19)، شيخ هادى سيروئى، مدنى، غلامعلى مانى

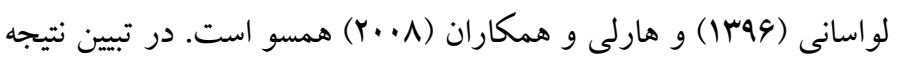

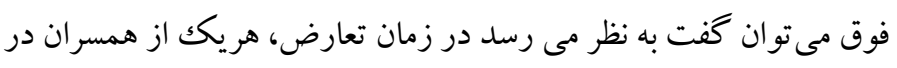

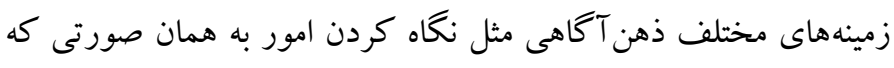

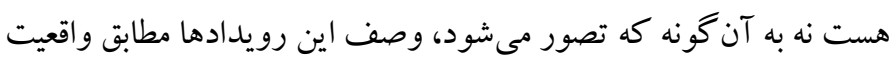

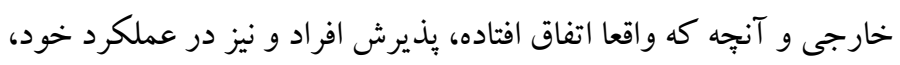

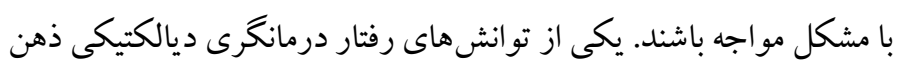

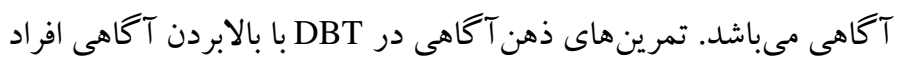

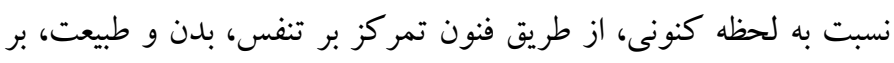

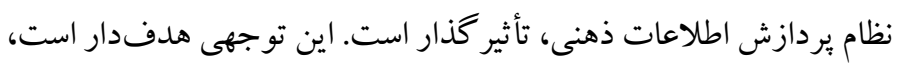
به همراه بذيرش بدون قضاوت در زمينه تجربه هاى درحال وقوع در لحظه

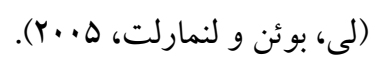

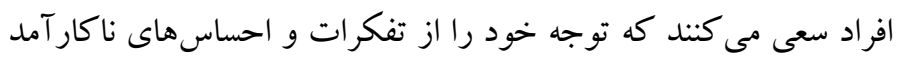
برغردانند و به جاى آن به بدن و محيط دوروبرشان بيشتر توجه كنند (بوئن،

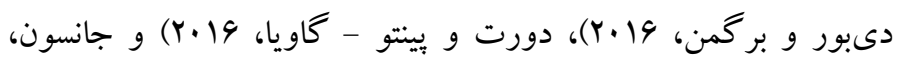

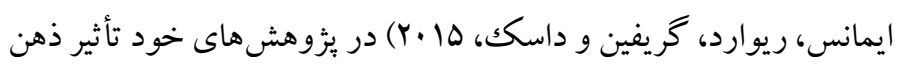

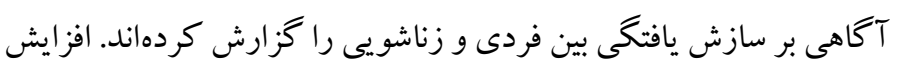

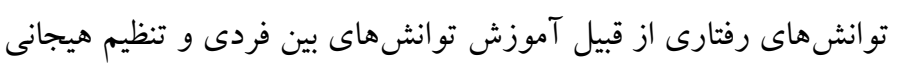

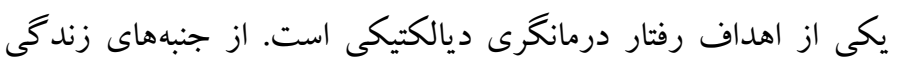

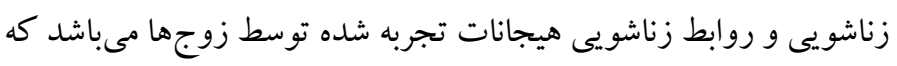

بحث و نتيجه كيرى

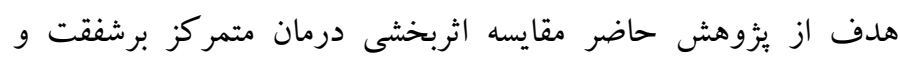

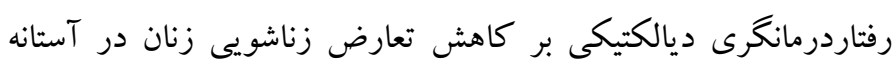

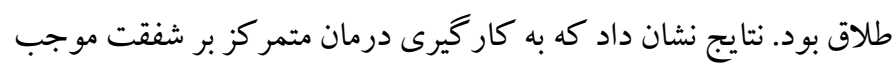

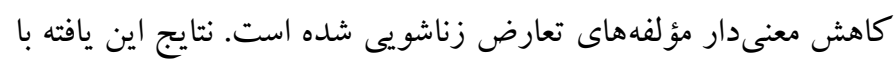

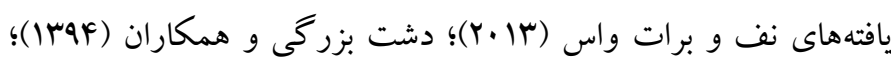

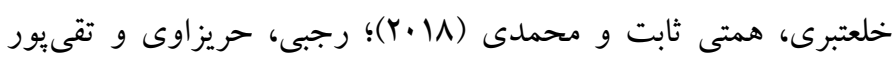
(Y.IV) در تبيين اين يافته مى توان كفت كه افراد با شفقت، قادرند با در نظر گرفتن

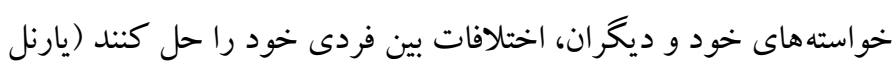

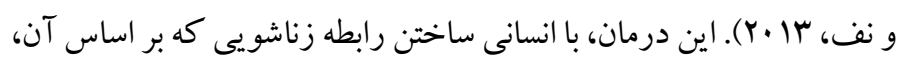

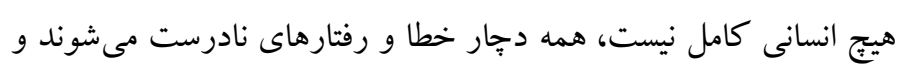

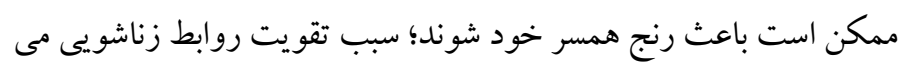

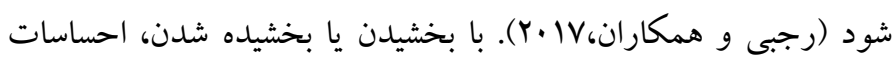

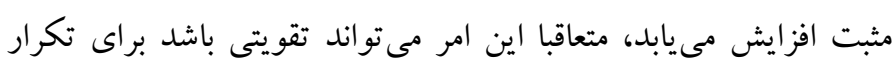

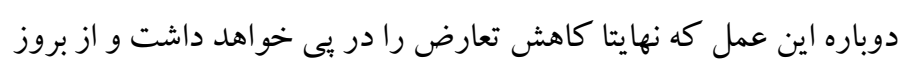

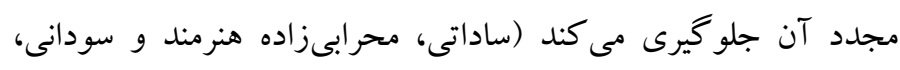

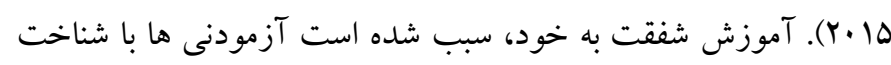

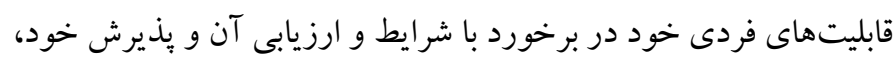

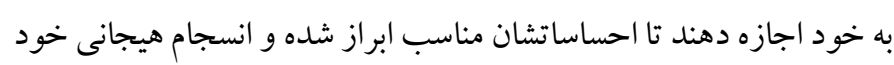

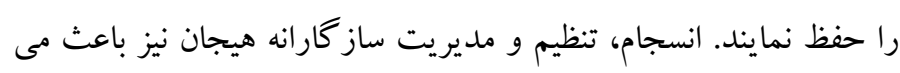

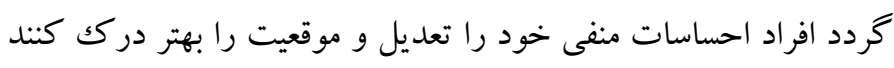

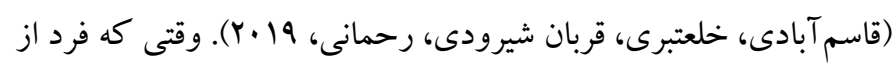

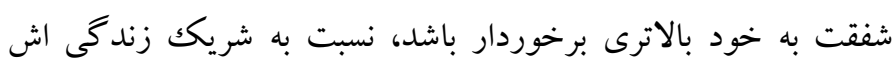

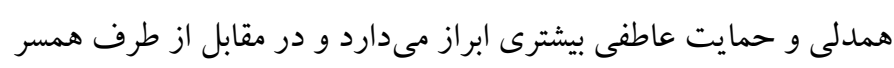

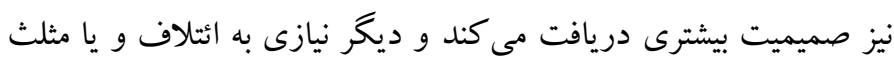

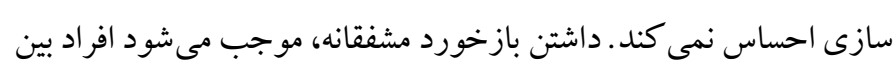
خود و سايرين بيوند احساس كنند و به همين خاطر بر ترس از كنار كذاشت داشتن

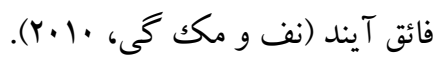
افراد خودشفقتورز، هيجانات مثبت توليد مى كنند (نف و و كاستيكان،

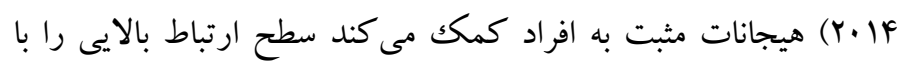
شريك خود برقرار كنند و يذيرش بالايى نسبت به همسر خود داشته باشند. 
از محدوديتهايى اين يثزوهش مىتوان به؛ استفاده از روش نمونه گيرى غير تصادفى، تكك جنسيتى بودن نمونه، احتمال اثر هالهاى به دليل انجام هر دو درمان توسط يكك نفر، عدم وجود دورههاى ييكيرى، اشاره كرد. برخى تحقيقات نشان دادهاند شفقت به خود در زنان كمتر (بونرت، 1 ا.Y) و انجام آن با سختى بيشترى همراه است؛ بنابر اين، بيشنهاد مىشود كه در يثوهش هاى بعدى در صورت امكان از جامعه زنان و مردان با هم استفاده شود و نتايج باهم مقايسه كردد. يِينهاد مى شود در تحقيقات آتى با استفاده از آزمون بيكيرى به سنجش يايدارى نتايج يرداخته شود و نيز متغيرهاى فرهنگى و جمعيت شناختى مثل مهاجربودن، وضعيت درآمد، تعداد فرزندان و اعتياد همسر به عنوان متغيرهاى تعديل كننده يثوهش مدنظر قرار

ملاحضات اخلاقى هييروى از ا صول اخلاق يُخوهش: اين مقاله بركرفته از ر سالهُ دكترى نوي سندة اول

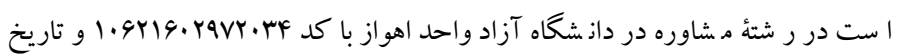
تصـويب يرويوزال آمارى از طرف اداره كل بهزيستى استان مازندران صادر شده است. ترونئ. حامى مالى: اين يزٔوهش در قالب رساله دكترى و بدون حمايت مالى مىباشد. نقش هر يكك از نويسند كان: نويسنده اول محقق اصلى اين يثزوهش است. نويسنده دوم استاد راهنما و نو يسندهُ سوم استاد مشاور رساله مىباشد.

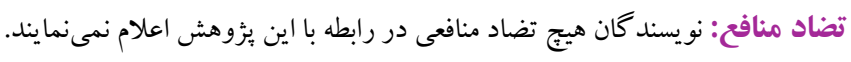
تشكر و قدردانى: بدين وسيله از اساتيد راهنما و مشاور اين تحقيق و نيز كار كنان مركز اورزانس اجتماعى سـارى كه در انجام اين تحقيق يارى نمودند تشـكر و قدردانى مى دى
توانايى تنظيم هيجان در اين امر بسيار مؤثر است (ليو، وانگك و شى، 19 •r). نظمبخشى هيجانى كمك مى كند تا آن دسته از عقايد نادرست هيجانى كه مورد يذيرش اشخاص هستند اصلاح شوند و آنها را ترغيب خواهد كرد تا ابتدا هيجانها را مشاهده كرده و سيس از يكديكر تميز دهند تا با به كاربردن آنها به معنى وسيع ترى دست يابند، بدين صورت از ميزان به وجود آمدن تجربيات هيجانى ناخوشايند مى كاهد (محمدى و همكاران، وM I I). در توانش بين فردى، افراد ضمن يادگيرى اين كه جِكونه مىتوان بدون

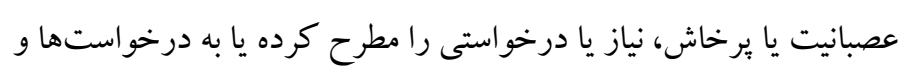
نيازهاى ديخران توجه نمود، متوجه مىشوند كه در برخى مواقع مى توانند

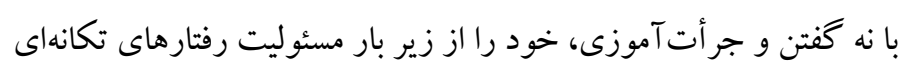
رها سازند. همجينين افراد ياد مى گيرند كه در صورت بروز تعارض در روابط، ضمن رعايت اصل احتر ام متقابل، به مذاكره براى حل و فصل مسئله بيردازند؛ بدون اين كه به رابطه آسيب وارد كنند (نجاريوراستادى و همكاران، يهس|). افرادى كه توانشهاى ارتباط موثر را فرا مى كيرند، به احتمال زياد مى تو انند به شيوهاى مطلوب با كفت و گوى كار آمد، اختلافات بين فردى خود را كاهش دهند و با به كار بردن به موقع عباراتى جون "(بخخشيد) (اعذرخواهى مى كنم") (متأسفم)" و آكاهى از اين كه جِه ميز ان عذر

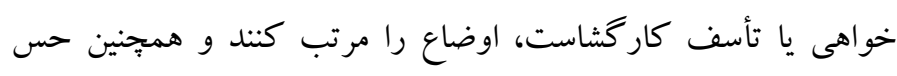
همدلى بيشترى به هم ابراز كنند و نسبت به احساسات هم، حساسيت زيادترى داشته باشند (جعفرخانى، صدقى و شعبانيان، IV · (Y). توانشهاى ارتباطى كمكك مى كند تا افراد علل بنيادين تعارض آسيبزاى خود را بشناسند، از روش هاى سازندهترى براى مواجه با آن استفاده كنند و كفتار خود را با آكاهى و حساسيت بيشتر و به طور مؤثرترى بيان كنند (فتحى

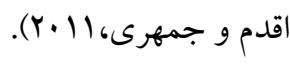




\section{References}

Alavi KH, Asghari Moghadam M.A, Rahiminejad A, Hojatollah Farahani H, Allame Z. (2017). Relationship between ambivalence over emotional expression and depression: The intermediary role of interpersonal problems.Journal of Thought \& Behavior in Clinical Psychology, 11(41): 27-36. (Persian). [Link]

Arabzadeh A, Sodani M, SHoa kazemi M, SHahbazi M. (2020). The Effectiveness of Dialectical Behavioral Therapy on Resilience and Psychological WellBeing of Couples Referred to Counseling Centers. QJCR. 19 (73):99-121. (Persian). [Link]

Baker D.A, Caswell H.L, Eccles F.J.R. (2019). Selfcompassion and depression, anxiety, and resilience in adults with epilepsy. Epilepsy \& Behavior, 90: 154-161. [Link]

Bonnert M, Olén O, Bjureberg J, Lalouni M, HedmanLagerlöf E, Serlachius E, et al. (2018) The role of avoidance behavior in the treatment of adolescents with irritable bowel syndrome: a mediation analysis. Behav Res Ther.105:27-35. [Link]

Bowen S, De Boer D, \& Bergman A L. (2016) the role of mindfulness as approach-based coping in the PTSD-substance abuse cycle. Addictive Behaviors, 64(1), 212-216. [Link]

Cleare S, Gumley, A \& O'Connor R. C. (2019). Selfcompassion, self- forgiveness, suicidal ideation.and self-harm: A systematic review. Clinical Psychology \& Psychotherapy, 26(5), 511-530. [Link]

Dahl S. Å, Hansen H. T, \& Vignes B. (2015). His, Her, or Their Divorce? Marital Dissolution and Sickness Absence in Norway. Journal of Marriage and Family, 77(2): 461-479. [Link]

Dasht Bozorgi Z, Askary M, Askary P. (2017). The Effecttivness of self-compassion on the intimacy attitudes and divorce tendency of Women refering to family counselling. Journal of Knowledge \& Research in Applied Psychology, 18 (1):38-45. (Persian). [Link]

DeCou R.C, Comtois K.A, Landes S.J. (2019) Dialectical Behavior Therapy Is Effective for the Treatment of Suicidal Behavior: A Meta-Analysis. Behavior Therapy, 50(1), 60-72. [Link]

Duarte J, Pinto-Gouveia J. (2016). Effectiveness of a mindfulness-based intervention on oncology nurses' burnout and compassion fatigue symptoms: A non-randomized study. International Journal of Nursing Studies, 64(1), 98-107. [Link]
Elaine Beaumont, C.J\& Hollins, M. (2016). Exploration of a training programme for student therapists that employs Compassionate Mind Training (CMT) to develop compassion for self and others. The Arts in Psychotherapy, 22, 5-13. [Link]

Emadi S, Mirhashemi M, sharifi H P. (2020). A structural model for prediction of couple burnout based on sensation seeking, perfectionism and emotion regulation strategies with the mediation of resiliency in married women. $J$ of Psychological Science, 19(92): 1022-1011. (Persian) [Link]

Fathiaqdam Q, Jomehri F. (2011) Comparison of the effectiveness of communication skills training in marital conflicts and hardship, female students of Islamic Azad University, Science and Research Branch. Journal of Education Research, 6(26), 126. [Link]

Fruzzetti AE. (2006). the High Conflict Couple: A Dialectical Behavior Therapy Guide to Finding Peace, Intimacy, \& Validation. 1nd ed. California: New Harbinger; 22-78.

Gaeta T, Dam A, Perrera T, Jones M, Dulani T. (2017). A Multicenter Study of Grit and it's Relationship to Burnout. Western Journal of Emergency Medicine: Integrating Emergency Care with Population Health, 18(5.1), 12-21. [Link]

Ghasem Abadi E, Khalatbari J, Ghorban Shiroudi SH, Rahmani M. (2019). Effectiveness of Schema and Commitment Therapy, Compassion-based Therapy, and Dialectical Behavior Therapy on Marital Conflict among Married Women in Social. Journal of Community Health, 6(2), 157-164. (Persian). [Link]

Ghodrati Torbati A, Nejat H, Toozandehjani H, Akbar Samari A, Akbari Amarghan H. (2020). Comparing the effectiveness of Dialectical Behavior Therapy and Compassion Focused Therapy on blood cortisol levels and self-control in drug abusers. Journal of Torbat Heydariyeh University of Medical Sciences, 7(4), 35-48. (Persian). [Link]

Gilbert, P. (2009). An introduction to compassion focused therapy. Advances in psychiatric Treatment, 15,199-208. [Link]

Gilbert, P. (2014). The origins and nature of compassion focused therapy. British Journal of Clinical Pschology, 53, 6-41. [Link]

Harley R, Sprich S, Safren S, Jacobo M, Fava M. (2008) Adaptation of dialectical behavior therapy skills.training group for treatment-resistant depression. The Journal of Nervous and Mental Disease, 196(2); 136-43. [Link] 
Irons C, \& Lad S. (2017). Using compassion focused therapy to work with shame and self- criticism in complex trauma. Australian Clinical Psychologist, 3, 47-54. [Link]

Jafarkhani Z, Sedghi M, Shabanian G, Manzari Tavakoli V. (2017). Comparison of marital adjustment, empathy and positive and negative emotions of fertile and infertile women in Kerman. Journal of Women \& Study of Family, 10(38), 119-136. (Persian). [Link]

Johnson, J. R., Emmons, H. C., Rivard, R. L., Griffin, K. H., \& Dusek, J. A. (2015). Resilience Training: A Pilot Study of a Mindfulness-Based Program with Depressed Healthcare Professionals. The Journal of Science and Healing, 11(6), 433-444. [Link]

Khalatbari J, Hemmati Sabet V, Mohammadi H. (2018). Effect of Compassion-Focused Therapy on Body Image and Marital Satisfaction in Women with Breast Cancer. Ijbd. 11 (3):7-20. (Persian). [Link]

Lathren C, Bluth K, Park J. (2019). Adolescent selfcompassion moderates the relationship between perceived stress and internalizing symptoms. Personality and Individual Differences 143: 36-41. [Link]

Leigh, L., Bowen, S., LanMarlatt, G. A. (2005). Spirituality, mindfulness and substance abuse. Addictive Behaviors, 30(1), 1335-1341. [Link]

Liu S, Wang Z, Lu S, Shi J. (2019). Dyadic analysis of childhood emotional maltreatment and maritalsatisfaction during the transition to parenthood: The mediating effects of emotion regulation strategies and psychological distress. Journal of Aggression, Maltreatment \& Trauma, 28(10), 1216-31.

Masumi tabar Z, afshariniya K, amiri H, Hosseini S A. (2021). The effectiveness of emotional schema therapy on emotional regulation problems and marital satisfaction of maladaptive women of the first decade of life. $J$ of Psychological Science, 19(95): 1506 -1497. (Persian). [Link]

McKay M, Wood JC, Brantley, J. (2007). The Dialectical Behavior Therapy Skills Workbook: Practical DBT Exercises for Learning Mindfulness, Interpersonal Effectiveness, Emotion Regulation \& Distress Tolerance. Ind ed. California: New Harbiinger; 7882.

Miller ML, Skerven K. (2017). Family skills: A naturalistic pilot study of a family-oriented dialectical.behavior therapy program. Couple and Family Psychology: Research and Practice, 6(2):79-93. [Link]
Minnott K L, Pedwrsen D, Mannon S. (2010). The emotional Terrain of parenting and marriage: emotion work and satisfaction. The Social Screuce Journal, 47 (4), 747-761. [Link]

Mirgain S, Cordova J V. (2017). Emotion skills and marital health: The association between observed and selfreported emotion skills, intimacy, and marital satisfaction. Journal of Social and Clinical.Psychology, 26(3), 941-967. [Link]

Mohamadi J, Gholamrezae S, Azizi A. (2015). Effectiveness of Dialectical Behavior Therapy on Quality ofSleep and Anxiety in Patients with Irritable Bowel Syndrome. IJPN, 3 (2):21-30. (Persian). [Link]

Najarpour Ostadi S, Akbari B, Khalatbari J. Babapour Kheiraldin J. (2019). The Comparison of the Effectiveness of Dialectical Behavioral Therapy Techniques Training and Quality of Life Therapy in Impulsivity among Female Undergraduate Students with Smartphones Addiction. Journal of Modern Psychological Researches, 14 (54): 151-174. (Persian). [Link]

Natasha F, Eman T, (2019). Integration of Structural Family Therapy and Dialectical Behavior Therapy with High-Conflict Couples. The Family Journal: Counseling and Therapy for Couples and Families, Vol. 27(1), 31-36. [Link]

Neff K.D, \& Costigan A.P. (2014). Self-Compassion, Wellbeing, and Happiness. Psychologie in Österreich, 2(3), 114-119. [Link]

Neff KD, Beretvas SN. (2013). the role of selfcompassion in romantic relationships. Self-Identity, 12(1), 7898. [Link]

Neff KD, McGehee P. (2010) Self-compassion and psychological resilience among adolescents and young adults. Self and Identity. 2010; 9(3):225-40. [Link]

Neff KD. (2012). The science of self-compassion. In: GermerC, Siegel R, editors. Compassion and Wisdom in Psychotherapy. New York: Guilford Press, 2012, pp: 79-92. [Link]

Nowlan K M, Georgia E J, Doss B D. (2017)Long-Term Effectiveness of Treatment -as-Usual Couple Therapy for Military Veterans. Behavior Therapy, In press, corrected proof, 32(4):163-181. [Link]

Parisouz A, Najarpoorian S, Mohammadi K. (2019). Effectiveness of Dialectical Behavioral Therapy on Marital Conflict and Interpersonal Processing of Married Women with Emotional Divorce. J Res Behav Sci, 17(2): 253-264. (Persian). [Link] 
Patrick S, Sells J N, Giordano F G, Tollerud T R. (2017). Intimacy, differentiation, and personality variables as predictors of marital satisfaction. The Family Journal, 15(2):359-367. [Link]

Pou J. S. (2019). Dialectical Behavior Therapy and Mentalization Based Treatment for Borderline Personality Disorder: Similarities, Differences, and Clinical Implications. Biola University. [Link]

Quinn GP, Keough M. (2002). Experimental Design and Data Analysis for Biologists. Cambridge: Cambridge University Press. [Link]

Ragabi GH. Harizavi M, taghipour M. (2017). Evaluating the model of the relationship between selfcompassion, marital empathy, and depression with mediating marital forgiveness in Female. Biannual Journal of Applied Consulting, 6(2), 1-22. (Persian). [Link]

Rezaei V, Fallah M, Vaziri S. (2020). Investigating the Causes of Divorce through Narrative Analysis.in Yazd City and Designing a Prerequisite Education based on the Causes of Divorce using a Hidden Learning Approach on the basis of Family, School, and Student .The Journal of Toloo e-behdasht, 19(1):73-83. (Persian). [Link]

Robinson S, Lang JE, Hernandez AM, Holz T, Cameron M, Brannon B. (2018). Outcomes of dialectical behavior therapy administered by an interdisciplinary team, Archives of Psychiatric Nursing, 32(4), 512-516. [Link]

Sadati E, Mehrabizadeh Honarmand M, Soodani M. (2015). The causal relationship of differentiation. neuroticism, and forgiveness with marital disaffection through mediation of marital conflict. Family Psychology, 1(2), 55-68. (Persian). [Link]

Seidabadi S, Noranipour R, ShafiAbadi A. (2021) The Comparison of the Effectiveness of SolutionFocused Couple Therapy and Imago Relationship Therapy (IMAGO) on the Conflicts of the couples referring to counseling centers in Tehran city. QJCR. 19 (76):4-23. (Persian). [Link]

Sheykhhadi R, Madani Y, Gholamali Lavasani M. (2017). Effectiveness of Dialectical Behavioral Therapy on Conflict Management Styles of High-Conflicted Couples. Journal of Health and Community Research Article: 11(3, 4): 47-55. (Persian). [Link]

Tajdin A, AleYasin A, Heydari H, Davodi H. (2021) Comparison of the effectiveness of compassionfocused therapy and reality therapy on alexithymia among male prisoner clients. J of Psychological Science. 19(95): 1519-1532. (Persian). [Link]
Voci A, Veneziani CA, Fuochi G. (2019). Relating Mindfulness, Heartfulness, and Psychological Well-Being: the Role of Self-Compassion and Gratitude. Mindfulness, 10 (2). 339-51. [Link]

Williamson H.C, Lavner J.A. (2019). Trajectories of marital satisfaction in diverse newlywed couples. Soc Psy Pers Sci, 11(5):597-604. [Link]

Wilson S.J, Andridge R, Peng J, Bailey B.E, Malarkey W.B, Kiecolt-Glaser J.K. (2017). Thoughts after marital conflict and punch biopsy wounds: Agegraded pathways to healing. Psych neuroendocrinology, 85: 6-13. [Link]

Yarnell L, Neff K.D. (2013). Self-compassion Interpersonal Conflict Resolutions, and Wellbeing. Self-Identity, 12, 1-14. [Link]

Quinn GP, Keough M. (2002) Experimental Design and Data Analysis For Biologists. Cambridge: Cambridge University Press. [Link] 